\title{
Abstracts of the Academic Medical Congress of Piaui, COMAPI, 2017
}

Poster Session

CASE REPORTS AND EXPERIENCE REPORTS

01. EVALUATION OF PHYTOCHEMICAL PROFILE AND MUTAGENIC POTENCIAL OF ETHANOLIC EXTRACT THE LEAVES OF Poincianella bracteosa (Tul.) L.P. Queiroz IN MICE

Johnny do Nascimento Alves', Alyne Pereira Lopes', Luciana Maria Fortes Magalhães Castelo Branco Couto', Eduarda Norberto Siqueira', Regina Maria Silva Sousa' and Pedro Marcos de Almeida'.

'State University of Piauí

INTRODUCTION: Poincianella bracteosa (Tul.) L.P. Queiroz. (Fabaceae), known as catingueira, is native to the Brazilian Caatinga and its leaves are used to treat diarrhea, hepatitis and anemia. However, there are still no reports on the mutagenic action of leaves and phytochemical studies are incipient. OBIECTIVES: To analyze the phytochemical profile and to evaluate the mutagenic potential of the ethanolic extract of leaves of $P$. bracteosa (EELPb) by means of the micronucleus test (MN) in peripheral blood of mice. METHODS: Leaves of $P$. bracteosa were collected in Teresina-PI and male Swiss mice (Mus musculus) were provided by Universidade Estadual do Piauí (UESPI). The study was approved by the Committee on Ethics in the Use of Animals (CEUAUESPI $5117 / 16$ ) with five groups (five animals per group). Leaves of P. bracteosa were dried $\left(45^{\circ} \mathrm{C}\right)$ for five days, crushed, subjected to extraction in ethylic alcohol and rotaevaporated to obtain the ethanolic extract. The phytochemical profile was performed by the colorimetric test with different reagents to identify the main primary and/or secondary metabolites of the EELPb. A solution of $1 \%$ dimethylsulfoxide (DMSO and distilled water) by gavage and cyclophosphamide (100 $\mathrm{mg} / \mathrm{kg})$ intraperitoneally were administered to the mice as negative (NC) and positive (PC) controls, respectively. Three doses of $\operatorname{EELPb}(20,40$ and $80 \mathrm{mg} / \mathrm{kg})$ were administered to the mice by gavage. After 24,48 and $72 \mathrm{~h}$, tail blood from each animal was collected for the preparation of two slides per animal. The slides were dried at room temperature, fixed in methanol (5 min), stained with Giemsa (15 min) and washed with distilled water. The presence of MN in each animal was determined by the count of 1000 normochromatic erythrocytes under an optical microscope $(1000 \mathrm{x})$. Data were analyzed by Kruskal-Wallis non-parametric test and Student-Newman-Keuls a posteriori test $(p<0.05)$ in the BioEstat 5.3 program. RESULTS: Only saponins were identified and at all times and doses of the EELPb, the presence of $\mathrm{MN}$ in the blood cells of the mice was not significant when compared to the NC. CONCLUSION: The results of the present study indicate that, possibly, the saponins of the EELPb did not result in the mutagenic action (MN) at the concentrations tested. However, further studies are needed to evaluate the mode of action of saponins in DNA.

02.

Poincianella bracteosa (Tul.) L.P. Queiroz: PHYTOCHEMICAL PROFILE AND ANTIMUTAGENIC POTENTIAL OF THE BARK AQUEOUS EXTRACT IN MICE BY THE MICRONUCLEUS TEST

Anna Catharina Feitosa Couto', Alyne Pereira Lopes', Mariana Leite Pereira', Pedro Igor Barros Santos', Regina Maria Silva Sousa' and Pedro Marcos de Almeida'.

'State University of Piauí

INTRODUCTION: Poincianella bracteosa (Tul.) L.P. Queiroz (Fabaceae), known as catingueira, is a tree native to Caatinga and presents insecticidal, antimicrobial, anti-inflammatory and antioxidant potential. However, studies on the phytochemical prospection of the bark and evaluation of damage and/or protective action on DNA have not yet been performed. OBJECTIVE: Evaluate the phytochemical profile and the antimutagenic effect in the simultaneous treatment of the aqueous extract of the bark
(AEB) of $P$. bracteosa by the micronucleus test $(\mathrm{MN})$ in blood cell of mice. METHODS: Bark from $P$. bracteosa was collected in Teresina (PI, Brazil). Male Swiss mice (Mus musculus) were provided by the vivarium from the Faculty of Medical Sciences (FACIME) at UESPI (PI, Brazil). This work was approved by the Ethics Commission for the Use of Animals from FACIME (CEUAUESPI 05902/15) with five groups (five animals per group). The phytochemical profile was performed by the colorimetric test to identify the main secondary metabolites of the $A E B$. On the negative control (NC), distilled water (by gavage) was administered to the mice in two days every $24 \mathrm{~h}$. On positive control (PC) distilled water and cyclophosphamide $(50 \mathrm{mg} / \mathrm{kg}$; by intraperitoneal) were administered on the first and second day, respectively. In the simultaneous treatment, on the first day was administered distilled water to the mice and on second day the AEB at three doses (10, 20 and $40 \mathrm{mg} / \mathrm{kg}$; by gavage) and cyclophosphamide, at the same time. After 24,48 and $72 \mathrm{~h}$, the blood of tail of each animal was collected for the preparation of two slides per animal. Slides were dried (24h), fixed in methanol ( 5 min.), stained with Giemsa ( 15 min.) and washed with distilled water. The presence of $\mathrm{MN}$ in each animal was performed by counting 2,000 normochromatic erythrocytes in optical microscope $(1000 \mathrm{x})$. The data were analyzed by Kruskal-Wallis test and "a posteriori" Student-Newman-Keuls $(p<0.05)$ in the BioEstat 5.3 program. RESULTS: The phytochemicals evidenced in the AEB of $P$. bracteosa were tannins and reducing sugars. The significant reduction of MN on AEB was observed after 24 (20 e $40 \mathrm{mg} / \mathrm{kg}$ ), 48 $(40 \mathrm{mg} / \mathrm{kg})$ e $72 \mathrm{~h}(20$ e $40 \mathrm{mg} / \mathrm{kg})$ when compared with PC. CONCLUSION: The data obtained demonstrated the antimutagenic potential of the AEB of $P$. bracteosa. Probably, the phytochemicals of $A E B$ reduced the deleterious effects of cyclophosphamide. Emphasizes the need for more studies to ensure this potential protective effect on genetic material.

03. PHYTOCHEMICAL PROSPECTION AND POTENTIAL ANTIMUTAGENIC OF AQUEOUS EXTRACT OF LEAF OF Poincianella bracteosa (Tul.) L.P. Queiroz IN BLOOD PERIPHERAL OF MICE BY MICRONUCLEUS TEST.

Mariana Leite Pereira', Pedro Igor Barros Santos', Anna Catharina Feitosa Couto', Rafael de Oliveira Magalhães', Regina Maria Silva Sousa', Pedro Marcos de Almeida'. 'State University of Piauí

INTRODUCTION: Poincianella bracteosa (Tul) L.P. Queiroz (Fabaceae), known as catingueira, is used in folk medicinein the treatment of worms, diarrhea and bronchitis. However, there are no reports in the literature about phytochemicals presence in leafs and DNA damage prevention and/or repair induced by cyclophosphamide (CYCLO). OBJECTIVES: Evaluate phytochemical prospection and the antimutagenic potential of the aqueous extract of leaf of $P$. bracteosa (AEL) in blood cells of mice, using the micronucleus (MN) test. METHODS: Leafs from $P$. bracteosa was collected in Teresina (PI, Brazil) and the male swiss mice (Mus musculus) were provided by the vivarium from the Faculty of Medical Sciences at UESPI (PI, Brazil). This work was approved by the Ethics Commission for the Use of Animals from FACIME (CEUAUESPI 05902/15) with eight groups (five animals per group). The phytochemical prospection was performed by colorimetric test whit different reagents to identify main secondary metabolites of AEL. In negative control (NC), distilled water was administered to the mice in two days every $24 \mathrm{~h}$. In positive control (PC), Distilled water and cyclophosphamide $(50 \mathrm{mg} / \mathrm{kg}$ ) were administered on the first and second days, respectively. In simultaneous treatment, distilled water was administered on the first day and in the second day, CYCLO and three doses of AEL (10, 20 e $40 \mathrm{mg} / \mathrm{Kg}$ ) at the same time. In post-treatment, the animals received CYCLO on the first day and three doses of AEL on the second day. Distilled 
water and AEL were administered by gavage and CYCLO by intraperitoneal. Blood of tail was collected after 24 and $48 \mathrm{~h}$ for the preparation of two slides per animal. Slides were dried at room temperature, fixed in methanol $(5 \mathrm{~min}$.$) , stained with$ Giemsa (15 min.) and washed with distilled water. The presence of $\mathrm{MN}$ in each animal was performed by counting 1,000 normochromatic erythrocytes in optical microscope (1000 x). The data were analyzed using the non-parametric of Kruskal-Wallis test and "a posteriori" the Student-Newman-Keuls test $(p<0.05)$ in the BioEstat 5.3 program. RESULTS: The chemical constituents of AEL was reducers sugars, tannins and alkaloids. After 24 and $48 \mathrm{~h}$, all doses of AEL in simultaneous treatment and post-treatment resulted in significant reduction of $\mathrm{MN}$ when compared to $\mathrm{PC}$. CONCLUSION: The data indicate that AEL phytochemicals possibly interacted with PC, promoting antimutagenic effect. However, more studies should be performed to ensure their potential protective effect on the genetic material.

04.

PHYTOCHEMICAL PROSPECTION AND EVALUATION OF THE
MUTAGENIC EFFECT OF THE ETHANOLIC EXTRACT OF LEAVES Jatropha mollissima (Pohl) Baill IN MICE

Rafael de Oliveira Magalhães', Caio Felipe Norberto Siqueira'; Eduarda Norberto Siqueira'; Johnny do Nascimento Alves'; João Gabriel Silva Morais' e Pedro Marcos de Almeida'.

State University of Piaui

INTRODUCTION: Jatropha mollissima (Pohl) Baill (Euphorbiaceae), known as "pinhão bravo", is a native specie from brazillian semiarid and used as healing, antitumor and antifungal. However, there are no studies on the mutagenic action of leaves in mice and studies on phytochemical profile are still incipient. OBJECTIVES: Evaluate the phytochemical profile and analyze the mutagenic potential of the ethanolic extract of leaf (EEF) of J. mollissima in cells blood of mice by micronucleus test (MN). METHODS: Leaves of 1 . mollissima were collected in Parnaiba (PI) and the mice male Swiss (Mus musculus) were from the vivarium from Universidade Estadual do Piauí (UESPI). The work was approved by Comissão de Ética no Uso de Animais (CEUA- UESPI 5116/2016) with five groups (five animals per group). Leaves were dried $\left(45^{\circ} \mathrm{C}\right)$, crushed, submitted to the extraction in ethyl alcohol and rotary evaporated until obtaining the EEF. The extract was solubilized in $1 \%$ dymetilsulfoxide (DMSO), filtered and the three doses $(1,10$ and $100 \mathrm{mg} / \mathrm{kg}$ ) were obtained. The phytochemical profile was performed by the colorimetric test to identify the main metabolites of EEF. The 1\% DMSO solution and distilled water, via gavage, and cyclophosphamide, via intraperitoneal, were administered to the mice, representing the negative (NC) and positive (PC) controls, respectively. In treatments, the EEF was administered to the animal in three doses $(1,10$ and $100 \mathrm{mg} / \mathrm{kg})$ via gavage. Tail blood was collected after 24 and $48 \mathrm{~h}$ to prepare two slides per animal, which were dried $(24 \mathrm{~h})$, fixed in methanol (5 min), stained with Giemsa (15 min) and washed in water. The MN amount in each animal was determined by the count of 2000 normochromatic erythrocytes in optical microscope (1000x) and the data were analyzed by non-parametric test of Kruskal-Wallis $(P<0,05)$, on BioEstat 5.3 program. RESULTS: The phytochemical analysis of EEF revealed the presence of flavonoids, alkaloids, reducing sugars, triterpenes and steroids. After 24 and $48 \mathrm{~h}$, all the doses of EEF revealed no significant difference of MN when compared to the negative group. CONCLUSION: These findings demonstrated that the presence of phytochemicals of EEF of I. mollissima resulted in no mutagenic action (MN) in the doses tested. However, further studies are necessary to establish a possible interaction mechanism of phytochemicals with the genetic material.

05.

THE IMPORTANCE OF RAISING AWARENESS AMONG FUTURE HEALTHCARE PROFESSIONALS IN VACCINATION AGAINST THE INFLUENZA VIRUS (myxovírus influenzae) IN THE MUNICIPALITY OF PINHEIRO - MA.

Pedro Henrique Silva Barros', Anne Karine Martins Assunção

'Federal University of Maranhão

INTRODUCTION: Healthcare-related technologies have surpassed the expectations with regard to tools used to prevent diseases, however, the influenza mortality rate in Brazil is among $0.09 / 100,000$ citizens, out of the 188 individuals that have died $78.7 \%$ presented at least one flu risk factor (2016). The statistics call for special attention to the necessity of combating flu epidemics, nevertheless, the disease can be easily prevented with vaccination. The deficit of flu vaccination can be attributed to the following reasons: urban myths; disbelief in vaccine effectiveness; and poor communication between doctors and patients, which can lead to a lack of information and understanding about the role of immunization. OBJECTIVES: This research focused on bringing awareness to future health care providers in the Universidade Federal do Maranhão (UFMA) - Pinheiro campus about the importance of the influenza immunization, particularly among high-risk populations. METHODS: In order to achieve a critical analysis of reflection, the problematization methodology based on Maguerez's Arch is implemented in the Medical and Nursing courses. The method of the arch consists of five important steps: observation of reality, key-points, theory, possible solutions and application of reality. These steps provide participants with the ability to critically reflect on the reality of the topic being discussed. The students had the opportunity to raise awareness among their classmates about the importance of the influenza vaccine through an informative lecture. The lecture was geared toward medical and nursing students, in which the following subjects were addressed: the physiopathology of the virus, how the disease can be transmitted, high-risk groups, symptoms, 2017 data on immunization coverage in Pinheiro and how future health care professionals can help improve the immunization coverage in the Municipality. Stickers were distributed as an outreach tool to emphasize the importance of vaccination. RESULTS: Students showed great interest on the issues presented in the lecture, highlighting the low influenza vaccination rates among high-risk populations. To help raise awareness students vowed to distribute informative stickers about the importance of vaccination to professionals in the healthcare field, particularly to primary care providers. Furthermore, students suggested that more training be offered to better prepare them to deal with high-risk populations in the future. The possibility of future informative lectures about the subject was also discussed. CONCLUSION: According to the results, the low vaccination coverage due to the lack of incentive, primarily, from doctors, emphasizes the need to educate medical and nursing students on the current critical situation, the tools available to overcome this barrier and how they can positively change the culture of the community.

06. NUTRITIONAL EVALUATION AND RISK IDENTIFICATION FOR CARDIOMETABOLIC DISEASES IN PICOS (PI) COMMERCIAL RESTAURANTS

Marcela Maria Lopes Costa1; Marina Santos Carvalho² Humberto Ferreira De Castro Filho ${ }^{3}$; Francisca Mariana Santos Silva ${ }^{3}$

1 State University of Maranhão, 2 Federal University of Ceará, 3 Federal University of Piauí

INTRODUCTION: Food is determinant in the quality of life, being responsible for the maintenance, prevention or recovery of health. However, the habit of eating outside the home intensified throughout the twentieth century, and began to collaborate for a gastronomic spread. Thus, meals outside the home reflect the health of the population, especially when associated with nutritional imbalance and, thus, may reflect even in the development of chronic noncommunicable diseases (CNCD). According to data from the Family Budgets Survey (POF) conducted between 2008 and 2009 by the Brazilian Institute of Geography and Statistics (IBGE), the prevalence of overweight and obesity increased in all age groups and income classes of the Brazilian population. It is estimated a prevalence of overweight and obesity, respectively, of $49.0 \%$ and $14.8 \%$ in the Brazilian adult population. In addition, $44 \%$ of diabetes problems, $23 \%$ of ischemic heart disease and $7 \%$ to $41 \%$ of certain types of cancer are attributed to overweight and obesity. OBJECTIVE: To evaluate the nutritional status of commercial restaurant diners in Picos and to identify the risks for cardiometabolic diseases. METHOD: Descriptive cross - sectional study conducted in adults in 7 commercial restaurants in Picos. Dietary habits were investigated through the application of a questionnaire and the diagnosis of the 
nutritional status and the cardiometabolic risk that were performed by the anthropometric evaluation. The data were tabulated and the descriptive analysis was performed in the Statistical Package for the Social Sciences (SPSS). The study protocol was submitted to the Research Ethics Committee of the Federal University of Piaui for consideration (CAAE 30957814.0.0000.5214). RESULTS: Participants demonstrated concern with choosing healthy foods referring to preference for salads and grilled preparations. As for the frequency of meals outside the home, most reported rarely attending commercial restaurants. The highest prevalence was eutrophy for women $(49.1 \%$ ) and overweight among men (50\%). Cardiometabolic risk prevailed, in both sexes, the absence of risk. CONCLUSION: The prevalence of overweight, especially for males, found among the participants is a public health problem in this population, and it is necessary to adopt measures that can reverse the growth of this prevalence.

07.

\section{CLINICAL AND EPIDEMIOLOGICAL ASPECTS OF ACCIDENTS BY SPECIFIC ANIMALS IN THE STATE OF MARANHÃO}

Kledson Sousa Rolins Marques Da Silva'; Marcela Maria Lopes Costa1; Alexandra De Oliveira Lopes ${ }^{1}$; Samara Belchior Caído1; Humberto Ferreira De Castro Filho²; José De Ribamar Ross'.

1 State University of Maranhão, ${ }^{2}$ Federal University of Piauí.

INTRODUCTION: Maranhão belongs to an area of great importance regarding the incidence of venomous accidents. As an example, Scorpio has the highest incidence of the country in the northeast with 31.5 cases per 100,000 inhabitants in 2014. In addition, health authorities in the state emphasize the need for health education for population and for health teams in order to encourage the decline of cases, as well as to make hospital care more efficient. However, in the Northeastern region, and especially in Maranhão, there are few published publications, and thus, the characteristics of venomous accidents in the state are little elucidated. Thus, to know the profile of these cases allows health organization strategies both for better preparedness in health care, and for population preparation in case of cases, in order to induce the victims to a better prognosis. OBJECTIVE: To determine the clinicalepidemiological profile of venomous accidents recorded in the state of Maranhão from 2011 to 2015. METHODOLOGY: Crosssectional, exploratory and descriptive study. Collection started on the TABNET website and in the SINAN, in order to gather prevalence data using the variables: cases per year, sex, age, race, time of sting / attendance, type of accident, classification final and evolution of the case. The data was gathered in Microsoft Excel spreadsheets for table study. RESULTS: In the established period, there were 10,818 venomous accidents in the state. The victims, in the majority, men $7,657(70 \%)$ and brown 7,778 (72\%), with age group of $20-39$ years $3,851(35,6 \%)$. Most of the cases presented a period of 1 to 3 hours between the bite and the health care 3,776 (35\%). The majority of cases are mild, 6,237 (57.65\%). Regarding the evolution of the cases, cure was obtained in $8,728(80.7 \%)$ of the cases and death was presented in 59 of the cases. CONCLUSION: The venomous accidents in Maranhão reach mainly men, mulattos and adults. They are, in most cases, ophidian accidents, classified as mild and presenting a high percentage of cure. Knowing the profile of these accidents provides more effective health strategies in order to promote better care, as well as boost preventive work. Promoting, thus, the decline in the epidemiological indices demonstrated.

08. ANTIMICROBIAL SUSCEPTIBILITY OF ESCHERICHIA COLI IN OUTPACIENT URINARY TRACT INFECTION

George Henrique Rodrigues dos Santos', Ginivaldo Victor Ribeiro do Nascimento², Guilherme Miranda Correia', Ana Maria Vilarinho Evangelista', Ligia Maria Rufino Borges Bezerra' and Lucas Noleto Lima'.

'Facid Devry

BACKGROUND: The urinary tract infection occurs when the bacteria reaches the urinary tract and attacks the mucosa of the bladder or kidney. When there is a renal injury, UTI is named pyelonephritis, that is a more sever disease. A bladder injury, in the other hand, is named cystis. The most common agent of UTI is Escherichia coli, a gram-negative enterobacteria. The goal of this study was to determine the susceptibility profile of Escherichia coli of outpatient urine cultures in Teresina, Piauí. METHODS: It is a cross-sectional, descriptive and quantitative study. This work was started after approval of CEP -FACID, a etic committee, and authorization of LACEN, a reference laboratory in microbiology of the state of Piauí. The data were collected from October 2016 to March 2017 and they were obtained by consulting the results of the urine cultures. It was included in the study individuals aged 16 years or over from October 2016 to March 2017. It was excluded from this study smudged tests and positive urine cultures without susceptibility test. The data were analyzed through the statistical software BioEstat 5.0, whose significance level was $p, 0.05$ and $95 \%$ confidence level through the $\mathrm{Z}$ and chi-square tests. RESULTS: A total of 2834 urine cultures were analyzed and only $11.5 \%$ of this test had a positive result. E. coli was the most incident with $78.5 \%$. Regarding the susceptibility profile of $E$. coli to antibiotics, carbapenems and amikacin were more sensitive, whereas ampicillin, ampicillin with sulbactam and sulfamethoxazole with trimethoprim had a higher resistance rate. There was also a low sensitivity of ciprofloxacin ( $56.3 \%$ ), mainly in men (23.7\%). CONCLUSIONS: It is concluded that ampicillin and ampicillin sulbactam are not antibiotics indicated for initiation of empirical therapy because of the high resistance rate. Ciprofloxacin, according to this study, also couldn't be indicated to empirical therapy in UTI.

\section{BONE METHSTASE OF CARCINOMA OF BREAST IN YOUNC PATIENT}

Eduardo Andrade Vasconcelos', Jackson de Sá Sousa', Deusdedith Carvalho Silva Neto', Higor Brenner Silva Lima', João Gustavo Medeiros Lago Sotero' and Adriano Rocha Alencar'. ' Facid Devry

INTRODUCTION: Breast carcinoma is one of the most common malignant tumors in women. It is also observed that patients with this disease are at greater risk of developing distant metastases, even after extensive periods of remission. More often, such recurrences manifest themselves in the bones, liver, and lung. We report a rare case of metastasis of breast carcinoma to the iliac bone in a young patient. CASE REPORT: J.N.N, 30 years old, female, brown, housewife, was admitted to UBS in the year 2014 with complaints of a palpable nodule in the right breast, painless with no visible changes. Patient denied family history of breast or ovarian cancer. The doctor requested a USG, with results of BIRADS-2 cyst, followed up and verified one year after the cyst progressed in size. The conduct was to continue the follow-up. In March 2016, the patient returned to UBS with complaints of right thigh pain and was referred to physical therapy. With the performance of the exercises, the pains progressed. It was performed MRI in June 2016 of the hip evidencing inflammatory arthropathy, which raised the suspicion of a basic disease. An active investigation was carried out with some exams, such as scans, hemogram and $\mathrm{CT}$, and the tomography showed osteolytic lesionsecondary to the underlying disease, suggesting bone metastase. In September 2016 a breast USG was performed, showing a spiculated solid lesion, poorly defined, at the level of the lower quadrants of the right breast, characterized by arboriform pattern of BIRADS-5 classification with presence of sentinel lymph nodes. Biopsy was performed on the iliac bone and right breast, confirming metastatic and intraductal carcinoma, respectively. FINAL CONSIDERATIONS: Due to the severity and rarity of the case of the patient under study, with no family history and very young, it is important to divulge it, with the prerogative to further elucidate this subject in the scientific literature.

\section{Melanocytic Melanoma in Paranasal Sinus}

Eduardo Andrade Vasconcelos'; Rafaella Nelice de Holanda Cardoso'; Jorge Everton de Medeiros Nogueria Júnior ${ }^{1}$; Jackson de Sá Sousa'; Cybelle de Meneses Costa Mouraª; Tovar Vicente Luz'

${ }^{1}$ Facid Devry, ${ }^{2}$ University Center UNINOVAFAPI

INTRODUCTION: Malignant melanoma of the sinus mucosa is a rare and aggressive tumor that affects patients over 60 years and 
without association with sex. Primary mucosal melanomas of the paranasal sinuses account for $1 \%$ of all melanomas. Nasal obstruction and epistaxis are the most commonly reported symptoms, although the symptoms are late and nonspecific, which delays diagnosis and worsens prognosis. Most common sinus locations are maxillary and ethmoidal sinuses. Traditional approach is surgery; radiotherapy is also used, but its efficacy is still discussed. CASE REPORT: M.M.C.R., 71-year-old female, retired, from Teresina-PI, sought a private hospital in this city, complaining of bilateral nasal obstruction more severe in the left nasal cavity and episodes of epistaxis two months ago. The otorhinolaryngological examination presented normal oropharyngoscopy, normal otoscopy, and in anterior rhinoscopy presented hypertrophy and pallor of inferior turbinates +++ / 4 bilaterally. She underwent nasal videoendoscopy, which revealed in the left nasal fossa polypoid aspect lesion with blackened spots having probable origin in middle meatus and extending to the rhinopharynx. An incisional biopsy of the lesion was performed and a computed tomography scan of the paranasal sinuses was requested. Pathological anatomy: little differentiated malignant neoplasm suggesting the accomplishment of immunohistochemistry. The presence of melanic pigment and sometimes alveolar arrangement favors melanoma. Immunohistochemical report: nasal melanoma, predominance of epithelioid cells, mitotic idice of 6-8 mitoses/undetected angiolymphatic invasion. Tomography of the paranasal sinuses: image with soft tissue density in the left middle meatus with posterior extension up to the rhinopharynx. After discussion with the oncology department of another hospital, nasal endoscopic surgery with removal of block lesion and adjuvant radiotherapy and chemotherapy was chosen. The otorhinolaryngological followup of the patient was maintained every 3 months with nasal videoendoscopy and paranasal sinus tomography. Approximately 2 years after the surgical procedure, the nasal endoscopy was visualized in the blackened lesion near the insertion of the horizontal portion of the middle left shell, a biopsy was performed confirming nasal melanoma, the patient is currently performing new radio and chemotherapy sessions.CONSIDERATIONS: Due to the rarity of the case, it is important to report it, reducing the scarcity of this subject in the scientific literature.

\section{Chronic Tuberculous Otitis Media}

Eduardo Andrade Vasconcelos'; Sheilane de Oliveira Moura²; Barbara Barros Leal3; Flávio Carvalho Santos'; Vitor Yamashiro Rocha Soares ${ }^{4}$

Facid Devry, ${ }^{2}$ University Center UNINOVAFAPI, ${ }^{3}$ State University of Piaui, 4 Flavio Santos Hospital

INTRODUCTION: Chronic Tuberculous Otitis Media (CTOM) is a rare bacterial infection caused by Mycobacterium tuberculosis, a slowgrowing strict aerobic bacillus. It is estimated that only 0.04 to $0.9 \%$ of the COM is caused by M. tuberculosis. The classic clinical presentation consists of the presence of multiple perforations in the tympanic membrane, painless otorrhea and peripheral facial paralysis. As this presentation is infrequent and CTOM is a rare disease, the diagnosis is not easy; often performed late and already in the presence of complications. The aim of this study was to describe a case of CTOM as a way of expanding knowledge about this rare disease. CASE REPORT: A 25-years-old male patient complaining of progressive hearing loss, tinnitus, otalgia and otorrhea in the right ear started 4 months ago. He was still dizzy. Facial mime was preserved. He also had mild dyspnea, fever and weight loss (10 kg). In the otoscopy, a polyp was visualized in the right ear, besides edema and purulent secretion in the external auditory canal (EAC). Hearing tests revealed anacusia in the right ear. Mastoid computed tomography showed: veiling of the middle ear and right mastoid, with mastoid discontinuity (osteolytic lesion). Cervical ultrasonography showed increased retroauricular lymph node. Serology for HIV was negative. X-ray of chest revealed a pulmonary consolidation with obliteration of the costophrenic sinus on the right. Direct sputum smear microscopy and culture of otorrhea for mycobacteria were positive for Koch's bacillus. The patient was diagnosed with pulmonary tubercle and CTOM. Venous antibiotic, corticosteroids and tuberculostatics were started. The patient evolved with improvement of pain, otorrhea and edema.
FINAL CONSIDERATIONS: Chronic Tuberculous Otitis Media (CTOM) is a rare disease. It should always be suspected of having a COM with atypical symptoms and no response to conventional treatments. Inadequate management leads to complications and a high morbidity rate for the patient.

\section{Neonatal mortality in the State of Piaui between 2010 and 2016}

Alice Rachel Bandeira de Araújo', Alécio de Oliveira Ribeiro², Candida Vanessa Silva Bacelar de Carvalho ${ }^{2}$, Indira Maria de Almeida Barros², Talita Carneiro², Nádia Pereira da Silva do Rêgo Monteiro ${ }^{2}$

${ }^{7}$ Facid Devry, ${ }^{2}$ University Center UNINOVAFAPI

INTRODUCTION: Neonatal mortality is the main component of infant mortality since the 1990 and appears as an sensitive indicator to conditions of life and health of a given population. The analysis of their main causes has special relevance for defining preventive actions more effective. In this context, the State of the Piaui offers one of the highest rates of infant mortality (TMI), and a significant portion is neonatal deaths. OBJECTIVES: Describe the profile of neonatal deaths and the associated factors in the State of Piaui. METHODS: This is a descriptive epidemiological study of neonatal mortality in the State of Piaui, between 2010 and 2016, using data available in the Department of Informatics of the unified health system (DATASUS), considering the following aspects: age group, avoidance and avoidable causes during the period studied. RESULTS: Between 2010 and 2016, there were 4,000 neonatal deaths, with a reduction in the number of cases over that period of time. Of these deaths, $77.48 \%$ were considered early neonatal and $22.52 \%$ late neonatal. The deaths by avoidable causes corresponded to $76.9 \%$ and $23.1 \%$ by not avoidable causes. Among avoidable causes, the most common were actions directed to pregnancy $(41.35 \%)$, attention to childbirth $(19.02 \%)$ and attention to newborn (14.40\%). Piaui presents neonatal mortality rate high if compared to other Brazilian States. This fact highlights the inequality of opportunities of access to healthcare in our country. Despite the high rate of neonatal mortality, the State follows the decline of this indicator in Brazil 25 years ago found. Most neonatal deaths focus within 0 to 6 days, in line with other studies. In addition, a significant portion of deaths are avoidable causes, similar to what occurs in all Brazil, which shows a deficiency of public policies related to children's health. One of the most common causes noted the need for improvement in attention to the birth and newborn. CONCLUSION: It is essential to provide subsidies for the implantation of the most appropriate health actions in order to reduce the high rates of neonatal mortality in the State of Piaui. The strengthening of the network of perinatal attention, with continuity of comprehensive care from the prenatal to neonatal assistance, is crucial in reducing avoidable causes.

\section{Myoepithelial Carcinoma in External Auditory Canal}

Eduardo Andrade Vasconcelos ${ }^{1}$; Sheilane de Oliveira Moura²; Luiz de Castro Bastos Filho3; Barbara Barros Leal3; Flávio Carvalho Santos'; Vitor Yamashiro Rocha Soares ${ }^{4}$ ' Facid Devry, ${ }^{2}$ University Center UNINOVAFAPI, 3 State University of Piauí, 4 Flavio Santos Hospital

INTRODUCTION: Myoepithelial carcinoma (CME) is a rare glandular epithelial neoplasia of the salivary gland with an incidence of less than $1 \%$ of all salivary gland tumors. It usually occurs in the parotid gland, but may also affect the maxillary sinus, nasal cavity, trachea, larynx, and lacrimal gland. CME from the external auditory canal (CAE) is very rare and only a few cases have been reported so far. CASE REPORT: A 43-year-old male patient with otalgia and hypoacusis and vegetative lesion, who had been exposed for 10 months by the left CAE. It denies smoking and alcoholism. Histopathological and immunohistochemical studies revealed low grade vascularized fusocellular malignancy with focal areas of coagulation necrosis compatible with myoepithelial carcinoma. Mastoid image exams revealed a heterogeneous solid hypodense mass involving the left outer ear with CAE obliteration, adjacent bone erosion and loss of definition of the tympanic membrane, with no signs of compromising the middle ear, but with parotid and mandibular condyle infiltration. Audiometry revealed moderate conductive loss in the left ear. Tumor resection 
was chosen through partial temporalectomy, partial parotidectomy and access to Fisch's infratemporal fossa type II. Patient presented residual tumor growth after the 3oth day after surgery. In view of this unusual pattern of rapid and progressive growth, the established surgical approach was the partial removal of the tumor and adjuvant radiotherapy and chemotherapy. After surgery, the patient was treated for 7 weeks with chemotherapy, and 40 sessions of radiotherapy, the lesion being still voluminous, refractory to treatment. FINAL CONSIDERATIONS: CAE myoepithelial carcinoma is rare, and there is no consensus as to what the ideal treatment would be. However, the treatment of choice is a complete resection of the lesion. Despite being a low grade lesion, local recurrence is common, found in up to $35 \%$ of cases. Due to the rarity of the case, it is important to report it, reducing the scarcity of this subject in the scientific literature.

14. EPIDEMIOLOGICAL PROFILE OF VISCERAL LEISHMANIASIS IN THE MUNICIPALITY OF MIGUEL ALVES, STATE OF PIAUÍ, BRAZIL Talita Carneiro', Luisa Rodrigues de Andrade', Camila Coelho Nóbrega Riefel', Adriana Sávia de Souza Araújo'. University Center UNINOVAFAPI

INTRODUCTION: Visceral leishmaniasis (VL) is a systemic zoonotic disease with a wide geographic distribution, being characterized potentially fatal. In Brazil, this disease represents a growing collective healthcare problem with high incidence rates, especially affecting the Northeast Region, being Piauí an endemic State. OBJECTIVE: To describe epidemiological aspects of human VL from residents living in Miguel Alves, State of Piauí, from January 2010 to December 2015. MATERIALS AND METHODS: A descriptive epidemiological study of VL was carried out in Miguel Alves, there were used additional data provided by "Sistema de Informação de Agravos de Notificação" (SINAN), being categorized per zones of residence, age group, sex, race and HIV-LV coinfection within the studied period. RESULTS: Seventy-seven VL cases were reported in Miguel Alves from January 2010 to December 2015, showing the greatest number of cases in 2011 (28.57). Brown-skinned people has predominated $(71.42 \%$ in accordance with the State percentage), mostly male (64.9\% according to the Brazilian literature) in the age group of $1-4$ years $(40.25 \%)$. This finding coincides with the literature, which is explained by the greater exposure of children to the phlebotomine in the peridomiciliary environment. The majority of cases belong to the urban zone $(54.54 \%)$, demonstrating that there is no pattern of disease transmission. HIV-VL coinfection was observed in only $2.6 \%$ of those reported, which shows results lower than the registered ones in the State. CONCLUSION: Results shown in this study indicate that $V L$ is still an endemic disease in Miguel Alves, in spite of the reduction in incidence since 2012. Therefore, policies and proposals for a vigilance, monitoring and control of this disease in the municipality are required.

\section{BLADDER HERNIATION BY DEFECT OF THE REAR WALL DEFECT} IN HERNIA DIRECT

Ana Maria Vilarinho Evangelista', Isadora Ferro Nogueira², Maria Eduarda Carvalho Santos de Araújo3, Maria Soares Leal de Moura' e Mauro André Goncalves Carvalho e Silva4. University Center UNINOVAFAPI, ${ }^{2}$ Federal University of Piaui, State University of Piaui, ${ }^{4}$ Facid Devry

INTRODUCTION: Inguinal hernias are the most prevalent in clinical practice, accounting for $75 \%$ of abdominal wall hernias. Most common in males and on the right side. The indirect ones have a congenital origin, secondary to the non-closure of the peritoneovaginal conduit. The direct ones are acquired due to weakening of the musculature of the posterior wall of the inguinal canal, related to age and with congenital and acquired collagen problems, occurring in the triangle of Hasselbach, region of greater fragility of the transversalis fascia. REPORT OF CASE: F.V.C., 67 years old, from São Miguel de Baixa Grande - PI, male, farmer, transferred to Teresina Emergency Hospital with history of right inguinal hernia 6 years ago, reporting bulging and sudden worsening of inguinal pain in the last hours. He evolved with abdominal distension and stopping the elimination of flatus and feces. He denied any urinary complaints. Examination: patient in general condition committed, conscious, oriented, eupneic, hypothermic, normotensive. Abdomen globous, hyperthympanic, painless to superficial and deep palpation and without signs of peritoneal irritation. Presence of hardened bulging in the right inguinal region, with mild pain at local palpation and no cutaneous alterations. A computed tomography scan of the abdomen was performed, revealing inguinal hernia on the right, with contents of thin loops and periwinkle edema. Diagnostic hypothesis: acute obstructive abdomen due to incarcerated inguinal hernia. Suggested conduct: emergency herniorrhaphy. Right inguinotomy was performed with defect identification on the posterior wall and bulky hernia sac. During resection, the bladder wall adhered to the bag was identified, with an accidental opening of the bladder. Performed vesicorrhaphy with polyglactin 1 in one plane. Opening of the hernia sac, containing viable thin loops, with initial suffering, but without ischemia. Reduction of the contents and resection of the bag was carried out with the reinforcement of the wall by the Bassini technique. On postoperative prescription, the patient used ceftriaxone and metronidazole, remaining in hospital for 48 hours. He was discharged with a bladder catheter of delay to be withdrawn after 15 days. In the postoperative follow-up, he did not report any complaints. FINAL CONSIDERATIONS Although the inguinal hernia is a frequent pathology in the medical routine, it is not common to find other abdominal viscera, such as the bladder, in joint herniation through a defect of the posterior wall.

\section{LINPH NODE TUBERCULOSIS}

Luma Araújo Borges de Moura', Ingrid Sales Lima', Isadora Ferro Nogueira', Mariana Oliveira Reis', Brenda Maria Batista de Carvalho Luz², Elisa Rosa Nunes Galvão'.

' Federal University of Piauí, ${ }^{2}$ Uninovafapi University Center

INTRODUCTION: Tuberculosis is an endemic disease in Brazil. The most common forms are pulmonary, pleural and lymph node. Among the extrapulmonary forms, pleural tuberculosis stands out as the most common form. On the other hand, the ganglionic one, also called tuberculosis of lymph nodes, is strongly associated with Acquired Immunodeficiency Syndrome (AIDS). The present study aims to report a case of lymph node tuberculosis in a patient without systemic symptoms. CASE REPORT: GSO, 40 years old, from Simplício Mendes-PI, sought care in the mastology clinic of the University Hospital of the Federal University of Piauí (HUUFPI) in March 2015, reporting a nodule in the right axilla wich has appeared three months ago, without associated systemic symptoms. She performed breast ultrasonography, which showed only right axillary lymph node enlargement, as well as a chest Xray, which did not present alterations. Gynecological history: G1P1A0, breastfeeding for 11 months. At physical examination: breasts with heterogeneous parenchyma, without palpable nodules, with right axillary adenomegaly. Aspirative Needle Puncture of the axillary lymph node was performed, and the material was sent for bacterial and fungus research. Molecular rapid test was positive for Mycobacterium tuberculosis and bacilloscopy was positive for Bacillus Acid Alcohol Resistant (BAAR). Treatment was performed for lymph node tuberculosis with rifampicin, isoniazid, pyrazinamide and ethambutol (RIPE) for six months, with remission of adenomegaly after three months of initiation of the therapeutic scheme. FINAL CONSIDERATIONS: The presence of lymphadenopathy may correspond to a series of pathologies. Among them, tuberculosis should always be considered as a differential diagnosis, due to the high prevalence of this pathology in our country. Due to the long duration of treatment and its side effects, strict follow-up is necessary.

\section{EPIDEMIOLOGICAL SURVEY OF VISCERAL LEISHMANIASIS IN PIAUI IN THE PERIOD OF 2010 TO 2015}

Ana Angélica Luz Pereira', Pedro Victor Rodrigues Pereira', Carla Maria de Carvalho Leite', Pablo Samarony Gomes Costa', José Rúther de Moura Pachêco' e Gabriel Medina Sobreira de Meneses'.

'Federal University of Piaui

INTRODUCTION: Visceral Leishmaniasis $(\mathrm{VL})$ is a chronic, severe and high lethality disease, which reaches more than 60 countries. In 
Brazil, it is caused by a protozoan of the species Leishmania (L.) chagasi, transmitted by vectors bugs. The disease is characterized by hepatospenomegaly, anemia and pancytopenia. The risk factors for the disease development include malnutrition, use of immunosuppressant drugs and HIV co-infection. The strategies of control are based on early diagnosis and treatment. OBJETIVES: To describe the epidemiological profile of patients with VL in the state of Piaui in the period of 2010 to 2015. METHODS: The quantitative research was accomplished by means of a retrospective epidemiological study in the period of 2010 to 2015 in the state of Piaui whose data source was the System of Information of Injuries of Notification (SIIN), the following criteria were considered: age range, evolution, sex and city of occurrence of VL. RESULTS: There were 1292 confirmed cases of VL in the analyzed period. The highest number of cases in Piaui was 288 $(22 \%)$ in 2014 and the lowest was 155 (12\%) in 2010, with an annual average of 258 cases. In the last three years, the number of cases raised, reaching $231(18 \%)$ in 2015 . Among the cities of Piaui, the highest number of cases belongs to Teresina: 1042 $(81 \%)$, followed by Parnaiba with $82(6 \%)$. The infection rates are higher in male sex, $837(65 \%)$, in the age average of 1 to 4 years (24\% of the cases) and 20 to 39 years (26\% of the cases). Regarding the evolution of cases, in the last four years, $52 \%$ of the cases evolved to healing; $35 \%$ had ignored evolution and, in $6 \%$ of the cases, there were deaths. CONCLUSION: The number of cases in Piaui is high, the capital, Teresina, shows the highest number of cases, which is probably associated to the environment change, as a result of the progressive and messy industrialization. Men are more affected because they are more exposed to bugs, in consequence of the work conditions. Children, as a result of theirs low immunity, are very affected as well. The mortality by VL was high in the study, which was caused by late diagnosis, associated to complications, leading to raise of death cases and to low percentage of healed individuals. These effects guide to the need of capacitate professionals to early recognition of suspects cases and, therefore, they will be able to do appropriate diagnosis and treatment.

\section{Epidemiological profile of leprosy in Piaui}

Renan Roberto Rodrigues Reis'. Matheus Gaspar de Miranda', Alice Rachel Bandeira de Araújo', Roberta Lillyan Rodrigues Reis².

' Facid Devry, ${ }^{2}$ Federal University of Piauí

INTRODUCTION: Leprosy is a communicable disease caused by the Mycobacterium leprae which causes skin lesions and peripheral nerves and may lead to physical and functional disability bringer. The Brazil concentrates $90 \%$ of the cases recorded in the Americas, having so great importance for public health. OBJECTIVES: The goal is to describe the epidemiological profile of the State of Piaui of 2010 to 2015 for new cases according to sex, age, operational classification, degree of incapacity and evolution of the disease. METHODS: Data were analyzed from leprosy notifications in Piaui among 2010 to 2015, present in the official database of the information system of reportable diseases (SINAN). It was analyzed the total notifications of new cases by sex, age,operational classification, degree of disability, classification and evolution of the disease. RESULTS: It was analyzed a total of 6943 notifications in the State with an average of 1157 cases/year. The male presented $3698(53.26 \%)$ notifications while $3245(46.73 \%)$ were female. Analyzing the age group occurred slightly predominance among the notifications of 50 to 64 years with 1752 (25.23\%) notifications. Of 35 to 49 years occurred 1734 (24.97\%) notifications and $1408(20.27 \%)$ were among 20 to 34 years. Analyzing the degree of incapacity, $4803(69.17 \%)$ cases were of degree zero and $1286(18.52 \%)$ were grade I. For operational classification, 3050 $(43.92 \%)$ cases were paucibacillary and $3893(56.07 \%)$ were multibacillary. Evolution occurred to cure in 5111 (73.61\%) cases and in just $89(1.28 \%)$ for deaths. CONCLUSION: The number of new cases presented small decrease over the years, as the distribution by sex in a discreet predominance by males, which can be explained by the greater human contact in the workplace, less concern with body and health related aspects, in addition to physiological and sociocultural aspects. The high proportion of cases with degreezero of incapacity at the time of diagnosis indicates efficiency on early detection, nonetheless the prevalence of multibacillary cases is troubling since this is the form infectiousof leprosy, so it is necessary to intensify the fight against the same. The high rate of evolution to curesuggestsadhesionand treatment efficiency. Given this, the effectiveness of the methods of prevention, diagnosis and treatment applied to combat leprosy.

\section{Epidemiological profile of tuberculosis in Brazil}

Renan Roberto Rodrigues Reis', Alice Rachel Bandeira de Araújo', Matheus Gaspar de Miranda', Barhbara Brenda Dias Garcez³, Roberta Lillyan Rodrigues Reis².

' Facid Devry, ${ }^{2}$ Federal University of Piauí, 3 State University of Maranhão

INTRODUCTION: Tuberculosis (TB) is a contagious infectious disease, caused by the bacillus Mycobacterium tuberculosis, transmitted by saliva, coughing or sneezing. It is currently one of the top 10 causes of death in the world, with 10 million new cases reported per year and over one million deaths. Brazil is part of the group of 22 countries prioritized by the World Health Organization (WHO), which account for $80 \%$ of all tuberculosis cases in the world. OBJECTIVES: To determine the epidemiological profile of tuberculosis cases in Brazil between 2010 and 2016 according to confirmed cases, sex, schooling and age of the patients. METHODS: Research was descriptive, retrospective, with a quantitative analysis of secondary data from the period of 2010 to 2016 reported in Brazil. The survey was carried out in the Information System of Aggravation and Notification (SINAN). The total number of notifications related to confirmed cases, sex, schooling and age group were analyzed. RESULTS: A total of 531,962 reports were analyzed in the country, with an average of $75,994.57$ cases / year. It was observed that $361,104(67.88 \%)$ reports were male and only $170,826(32.11 \%)$ were female. Analyzing the age range, there was a predominance of reports in the intervals of 20 to 29 years, with $122,718(23.07 \%)$ and 30 to 39 years of age, with $117,169(22.03 \%)$ cases reported. In addition, $170,013(31.95 \%)$ of the notified patients had incomplete primary education and 156,001 $(29.32 \%)$ were illiterate. CONCLUSION: There was a predominance of notifications in the age group of 20 to 39 years, this may have occurred due to being an interval in which the population is economically active. As for males, the large number of reports may be related to a combination of biological, social, cultural and economic components. Patients with low educational level were the most affected, which allows to infer that social and economic aspects influence the transmission of the infectious agent and the increase of the disease in the vulnerable populations. The number of cases remained constant indicating the need for more effective primary prevention, making it essential to develop more specific tuberculosis control strategies for vulnerable groups of contamination.

\section{Analysis of Control Program of Schistosomiasis in the} Northeast of Brazil from 2010 to 2016

Indira Maria de Almeida Barros', Alécio de Oliveira Ribeiro', Alice Rachel Bandeira de Araújo², Candida Vanessa Silva Bacelar de Carvalho', Talita Carneiro', Keylla Borges Bacelar de Carvalho'.

1 Uninovafapi University Center, ${ }^{2}$ Facid Devry

INTRODUCTION: Schistosomiasis is an endemic disease in Brazil and constitutes an important public health problem. In this context, the Program for Control of Schistosomiasis (PCE) was created, enabling more than 12 millions treatments throughout the country, mainly in the northeast region. OBJECTIVE: To analyze the effectiveness of PCE in the northeast of the country from 2010 and 2016. METHODS: This is a descriptive and quantitative analysis using secondary informations provided by the Department of Informatics of the Brazilian National Health System (DATASUS), in the period studied respect to schistosomiasis in the Brazilian Northeast, selecting some aspects conveyed in PCE. RESULTS: During the period, PCE worked with 5,921,985 people, and in 2010, $1,223,364$ people participated, while in 2016 , only 451,571 . A total of 4,299,574 coproscopies were performed, observing 208,996 cases of confirmed schistosomiasis (\% positivity of 4.86 ) and 828.616 of other verminoses. The state of Alagoas had the highest number of notifications, while Piauí had only 1 reported case. In relation to 
the intensity of intestinal infection (expressed in eggs per gram of faeces), $72.6 \%$ were considered mild, $21.08 \%$ moderate and $6.32 \%$ severe. It is evidenced that PCE affects a significant portion of the Brazilian population and that there has been, in the last 5 years, a reduction in the number of people assisted by PCE. On the other hand, the number of serious forms has decreased, which corroborates the effectiveness of the program with regard to early diagnosis. A large part of the exams diagnosed, in addition to schistosomiasis, other parasites, which indicates that the population segments analyzed are subject to poor health conditions. This is an expressive risk factor that contributes to the persistence of the disease. Alagoas is the state with the largest number of cases, which confirms that this parasite is associated with poverty and low economic development, since this state is the 2nd poorest in the country. In addition, this analysis suggests underreporting of cases, since in the state of Piaui was presents only 1 case in the cited period. CONCLUSION: PCE has decreased in the last years, although schistosomiasis is still a threat to the health of the Northeastern population. This therefore compromises the effectiveness of the program. So, it is evident the need for continuous monitoring of PCE and its implementation in municipalities not yet included.

\section{EVALUATION OF THE GENOTOXIC EFFECT OF THE Jatropha} mollissima (Pohl) Baill BY COMET ASSAY

Caio Felipe Norberto Siqueira'; Eduarda Norberto Siqueira'; Luciana Maria Fortes Magalhães Castelo Branco Couto'; Jéssica Ohana de Alencar Ferraz'; Fabrício Pires de Moura do Amaral' e Pedro Marcos de Almeida'.

' State University of Piauí

INTRODUCTION: Jatropha mollissima (Euphorbiaceae), popularly known as "pinhão bravo", is endemic to the semiarid region of northeastern Brazil and widely used in popular therapy. Recent studies have demonstrated important bioinseticidal and phytotherapeutic potential. OBJECTIVES: Evaluate the genotoxic potential of the ethanolic extract of leaf of $\%$. mollissima in cells blood of mice by comet assay. METHODS: Leaves of I. mollissima were collected in Parnaíba (PI) and the mice males Swiss (Mus musculus) were from the vivarium from Universidade Estadual do Piauí (UESPI). The work was approved by Comissão de Ética no Uso de Animais (CEUA- UESPI 5116/2016) with five groups (five animals per group). Leaves were dried $\left(45^{\circ} \mathrm{C}\right)$, crushed, submitted to the extraction in ethyl alcohol and rotary evaporated until obtaining the ethanolic extract. The $1 \%$ solution of dimethylsulfoxide (DMSO and distilled water) via gavage and cyclophosphamide (100 mg/kg) intraperitoneally were administered to the mice as negative control (NC) and positive control (PC), respectively. Three concentrations of the ethanolic extract of the leaf $(1,10$ and $100 \mathrm{mg} / \mathrm{mL})$ were administered to the mice via gavage. After $4 \mathrm{~h}$, a drop of blood from the tail of each animal was collected and stored in heparin eppendorfs. Then $10 \mu \mathrm{L}$ of blood were added to $100 \mu \mathrm{L}$ low-melting agarose $(0.75 \%)$ and $80 \mu \mathrm{L}$ of that solution were distributed into two pre-coated slides with common agarose $(1.5 \%)$. The slides were incubated in lysis solution (18 h) and in electrophoresis run (15 min, $300 \mathrm{~mA}, 25 \mathrm{~V})$. The slides were neutralized and stained with DAPI. Fifty nucleoids per slide were analyzed by fluorescence microscopy $(400 \mathrm{x})$ and the damages were quantified and classified into five classes (o to 4 ) to perform the calculation of frequency and damage index. The data were analyzed by test of Kruskal-Wallis ( $p<0.05)$, on BioEstat 5.3 program. RESULTS: At all concentrations evaluated after 4 $h$, the frequency and damage index of the extract were not significant when compared to the NC. CONCLUSION: The results showed that the ethanolic extract of the leaves of $/$. mollissima showed absence of genotoxic activity. However, more studies are needed to ensure its phytotherapeutic use.

22.

EPIDEMIOLOGIC PROFILE OF PERTUSSIS IN BRASIL (2016)

Jeferson Anderson Medeiros', José Walter Lima Prado', Wemerson Magalhães Medeiros².

' ITPAC, ${ }^{2}$ INTA

INTRODUCTION: Pertussis is an acute infectious disease of nationally compulsory notification. A transmissible condition caused by Bordetella pertussis, which specifically compromises the respiratory tract, characterized by paroxysms of dry cough. Clinically, the disease progresses in three successive phases: catarrhal, paroxysmal and convalescence. occurs under endemic and epidemic forms. This disease presentes high morbimortality in infants. OBIECTIVES: To expose the prevalence of confirmed cases of Pertussis in Brazil in 2016, and correlate with the literature. To describe the profile of the age group, race, gender, notification criteria and the cases evolution of Pertussis according to each state of notification, at the Sistema de Informação de Agravos de Notificação (SINAN), in 2016. METHODS: This is a descriptive epidemiological study. It was used the website datasus.saude.gov.br to obtein data, through the reported cases of pertussis in 2016. The research has been done through the links: "age group", "race ","gender"," confirmatory criterion" and "case evolution " according to "state of notification". Thus it was possible to obtain material for analysis in tables. RESULTS: According to SINAN, in 2016, 411 confirmed cases of pertussis were reported in Brazil. of these, $56.4 \%$ were patients younger than one year-old, $49.6 \%$ were classified in white race, $53.7 \%$ were female, $52.3 \%$ were under investigation and $90.9 \%$ were healed cases. The state of São Paulo presented the highest prevalence of cases, $20.9 \%$. CONCLUSION: Although there is a predominance of prevalence in certain state, gender and race, according to the government, there is no preferential geographic distribution or individual characteristic that predisposes to pertussis, other than the presence or absence of specific immunity. The morbidity of pertussis in Brazil was already high, but it fell due to the increase in vaccination coverage, mainly since 1998. However, in recent years outbreaks of pertussis have been recorded. The under-age group concentrates most of the new cases. This is probably due to the severity of Pertussis clinical in this age group, which, in turn, leads to greater demand for health services and more diagnosed cases.

\section{The Importance of monitoring in academic education and} the factors that influence interest in monitoring

Francisco Pedro Olimpio de Albuquerque Sales'; Antonio Levy Carvalho Nobre'; Maria Mariana Rocha Gomes'; Cicero Igor Simões Moura Silva'.

'UNINTA;

INTRODUCTION: Monitoring is a pedagogical support service that aims to promote the development of technical skills and theoretical deepening, providing the academic improvement. The monitoring of the school of medicine of the Higher Institute of Applied Theology - INTA aims to promote the deepening of immunology theory and is linked to the course of defense and aggression mechanisms offered during the third semester of the curriculum. The monitoring project promotes interdisciplinary actions and helps the students to have the contents in the vision of a student and a professor, assisting the professor, facilitating and improving the students' learning, arousing interest in the importance of the course. OBEJECTIVES: The objective of this research is to evaluate the importance of the monitoring in the university education and which factor influences the students to attend the meetings of the project. METHODS: This cross-sectional study was carried out by 55 people who attended the classes of the third semester. The research method used was a questionnaire with closed questions. The data collection occurred in a single moment: at the end of the course of defense and aggression mechanisms of two groups of students, in the second semester of 2016 and in the first semester of 2017. The data collection of the students occurred in the classroom, being the time of approximately 30 minutes. There was no need to submit the research project for analysis by the Ethics Committee, due to Resolution No. 510, of April 7, 2016 of the National Health Council. RESULTS: Among the respondents, $98.18 \%$ thought the monitoring was important for academic training and $1.81 \%$ did not know how to respond. $21.42 \%$ answered that the knowledge of the monitors is the factor for searching the monitoring, $26.78 \%$ answered that it was the didactics of the monitors, $8.92 \%$ the availability of the monitors and $42.85 \%$ answered that it is the performance in the program. CONCLUSION: From this study, it is evident the importance of the practice of monitoring by medical students. The 
students benefited by the project, demonstrated that the performance in the program is the main factor that influences to seek the monitoring.

24.

\section{VIABLE PREGNANCY IN PATIENT WITH UTERUS DIDELPHYS: CASE REPORT}

Jordan Carvalho Sousa', Thaís Almada Bastos', Sávio Câmara Vieira de Andrade', Ezequiel Conçalves da Costa', Ediane Morais de Sousa', Leonam Costa Oliveira'.

Federal University of Piauí

INTRODUCTION: Uterine malformations are uncommon findings, secondary to failures in the development, fusion or reabsorption of Müller's ducts. When there is a total failure of the fusion, there is the uterus didelphys. This finding represents $26 \%$ of uterine malformations, presenting a prevalence of $0.1 \%$ among fertile women, being characterized by duplicity of vagina, cervix and uterine body. It is associated with infertility and represents $15 \%$ of gestational losses in the second trimester. CASE REPORT: Woman, 29 years old, never been pregnant, regular menstrual cycles, asymptomatic, routine gynecological consultation. During specular examination, the cervix presented two external cervical orifices. Endocervical cells were collected by inserting the brush into both orifices, and the equipment passed through without difficulties. The patient performed ultrasound, showing, in transverse and longitudinal sections of the uterus, two endometrial echoes with duplicated uterine cavities; two uterine cervix and endocervical canals were also evident. Due to the suspicion of malformation, magnetic resonance of the pelvis was requested, observing a uterus didelphys, characterized by duplicity of the body and uterine cervix; expansive formations were not observed in the adnexal regions, nor free liquid in the pelvic excavation. About a year later, the patient became pregnant spontaneously and was referred to high-risk prenatal care. During pregnancy, progesterone was instituted until 34 weeks' gestation to prevent preterm birth. Laboratory and ultrasound examinations showed no alterations. At 36 weeks, the patient entered labor, undergoing cesarean section, which occurred without intercurrences. The newborn weighed 2.1 $\mathrm{kg}$, Apgar 8-9. After 3 days, mother and son were discharged. Currently, the patient is followed up in ambulatorial care without menstrual or sexual life changes, only on contraceptive use. FINAL CONSIDERATIONS: Uterine malformations are associated with placental abruption, intrauterine growth retardation and prematurity, which is in line with the case. In addition, the uterus didelphys is highly associated with infertility, being the case described a differential considering the expected for a woman with this malformation. There must be reinforced the importance of early diagnosis of malformation and gestation for the better conduct in its clinical approach, such as the use of progesterone to prevent prematurity.

EPIDEMIOLOGICAL ANALYSIS OF CASES OF ACCIDENTAL TETANUS OCCURRING IN PIAUÍ AND NORTHEAST

Alice Rachel Bandeira de Araújo', Clara D'Maria Lopes Raposo Sousa e Sousa', Francisco Pereira da Silva Filho', Isabele Ferreira da Silva', Renara Valadares', Deuzuita dos Santos Oliveira'.

'Facid Devry

INTRODUCTION: The fatality attributed to accidental tetanus did not fall significantly in the last decade, which shows the need for an epidemiological screening of high-risk groups, with the prevention and early detection of cases. Despite of possess vaccine-cheap and free access, still causing the death of children, adults, and especially the elderly. The largest occurrences of tetanus are present in underdeveloped countries, due to low vaccination coverage. According to data from the Ministry of health, in the period from 1998 to 2008, people male and aged between 25 and 64 years are the most affected. OBJECTIVES: Charting the epidemiological profile of the group more vulnerable to harm and deaths by accidental tetanus and analyze it in Piaui and in the Northeast. METHODS: This is a retrospective quantitative comparative epidemiological study, whose data source is the DataSUS, through secondary data information system of reportable harm (SINAN) in Piaui and in the Northeast, in the period from 2010 to 2016. RESULTS: In the Brazilian Northeast, showed the presence of 965 cases of unintentionaltetanus and these 47 occurred in Piaui, mostly aged among 40 and 59 years. Among the cases analyzed in this region, 865 concernsto males, of which 43 are in Piauí. That, according to the literature, is related to the reduction of antibody in this age and less monitoring of vaccine situation for the male population, since women carry out immunization against tetanus during the gestational period. In addition, the urban area has been shown with a greater number of cases, in line with other similar studies. And as for the evolution in the Northeast there were 300 deaths caused by accidental tetanus and, of these 13 occurred in Piaui. In addition, it was noticed that from 60 years, both in the Northeast, and Piauí, it is increased the chance of death. CONCLUSION: It was noted that most cases of accidental tetanus concentrates in the Northeastern region, in men belonging to the age group 30-65 years and residents of the urban environment. In addition, the evolution in cases of accidental death for tetanus is increasing with increasing age, and, in age groups between 40-80 years, the chance of cure comes to negligible values. It was to be no significant differences between the cases of accidental tetanus in the Northeast in relation to the proportion of cases of tetanus in Piaui.

\section{CLINICAL AND EPIDEMIOLOGICAL PROFILE}

OF ESPIENECTOMIES IN A URGENT HOSPITAL OF TERESINA

Guilherme Miranda Correia3, George Henrique Rodrigues dos Santos', Gleycianne da Silva Oliveira Drumont Vieira' Sanrrangers Sales Silva ${ }^{4}$, Guilherme Victor Sousa Medeiros $^{2}$, Welligton Ribeiro Figueiredo ${ }^{3}$.

1 Uninovafapi University Center, ${ }^{2}$ Federal University of Piaui, 3 Facid Devry, 4 State University of Piauí

INTRUDUCTION: the spleen is an abdominal solid organ, located in the left hypochondry. It is the largest lymphoid organ of the human body, the most important function is mechanical filtration aiding the removal of senescent hemacies. Various pathologies, including hematological and non-hematological diseases, both benign as malignant, constitute possible indications for esplenectomy. In the non-hematological causes, the main cause is splendid traumatism, the most common type of isolated traumatism found in abdominal traumes. Esplenectomized patients have a normal response to the re-immunization of antigen first found before esplenectomy, but does not demonstrate an excellent response to exposure to new antigens. OBJECTIVES: identify and evaluate the causes of esplenectomy in an urgent hospital and to make a correlation between these surgeries and their epidemiological variables. METHODS: information was obtained by review of pronouns of all patients submitted to esplenectomy in the period of august/2009 at august/2014 at teresina public hospital of reference. The following variables were analyzed: age, gender, civil state, schooling, procedure and reason of the high. For statistical analysis it was used only basic statistics. RESULTS: the study revealed that $84.53 \%$ $(n=295)$ of the patients submitted to emergency esplenectomy were men and the pre-condition was unmarried, corresponding to $56.46 \%(n=197)$ of the sample. The predominant age group of the operated patients are between 21-30 years with $28.65 \%(n=100)$. The greater incidence of trauma in the group of young and adults of male sex conditions with the literature and is associated with the increase of risk behavior in that age group due to exposure to alcohol and illicit drugs. In addition, $40.40 \%(n=141)$ of the patients presented incomplete fundamental teaching. As source $56.16 \%(n=196)$ was from the inside of piauí. In relation to the reason of the high $77.36 \%(n=270)$ presented high with the improvement of the initial clinical framework. CONCLUSION: conclusion that men, adults and single people represent the majority of esplenectomy cases in a theresin urgent hospital. 
27. REPORT OF A CAMPAIGN ON HYPERTESION MADE IN THE CENTRAL MARKET OF SOBRAL

Denise Helena Aparecida da Silva Vieira', Jhonyson Antonio Oliveira Marques', Wylston de Moraes Caldas Filho', Gabriel Luan Batista de Ávila', Karine Magalhães Fernandes Vieira', Hellen Keller Ávila Vasconcelos².

' Federal University of Ceará, ${ }^{2}$ Uninovafapi University Center

INTRODUCTION: Sistemic Arterial Hypertension is a usually underestimated disease by its silent character and insidious evolution. Estimates based in isolated populational studies says that the prevalence of SAH in our contry is around $30 \%$ in adult population. In Ceará, in 2012, were registered by hipertense monitoring system, obtained from DATASUS, 16.142 people, 1.034 of these just in Sobral. With the aim of promoting integration actions between medicine students and the public, was developed a campaign by students of Sobral Medical Development Nucleus (NUDEMES), project that belongs to UFC - Federal University of Ceará, in order to sensitize public to SAH. OBJETIVES: Aware the population of Sobral, present in the Market, about the risks of morbidity and mortality in hypertensive people and main prevention methods. METHODS: The campaign occured on June 7 2017 at Central Market of Sobral, located downtown. For choosing the place, were taken into account the extensive flow of people and the possibility of many of them don't get the chance to go to Health Center in their hometowns. About 30 people adhered the campaign. All of them had their blood pressurfe checked and were made aware by NUDEMES members about SAH risks and forms of prevention methods. RESULTS: After people approach, it could be noticed that they were aware of necessity and importance of antihypertensive drugs use as healthy food like poor salt and fat diets. Was detected a significant amount of people who declared cronic hypertension but didn't search for Health Centers for monitoring. It was found that women approached searched for medical services more often than men. Futhermore, the ones who said be hypertensive declared medication use and regular blood pressure check. CONCLUSION: The population was welcoming to the campaign in that place. Was observed the need to encourage male population to search medical assistence more often than they do.

\section{ANALYSIS OF PERCEPTION OF THE SOBRALENSE POPULATION} ABOUT ARTERIAL HYPERTENSION

Jhonyson Antonio Oliveira Marques', Karine Magalhães Fernandes Vieira', Gabriel Luan Batista de Ávila', Wylston de Moraes Caldas Filho', Raissa Carvalho Peixoto', Monallisa Amanda Ximenes Mesquisa dos Santos ${ }^{1}$

' Federal University of Ceará

INTRODUCTION: Hypertension is the most common cardiovascular disease. Besides the correlation between the prevalence of hypertension and variables such as age, sex and race, there are also the attribution of variables such as education and presence or absence of some habits as risk factors. With a new, more special look at basic health care, preventive measures are credited with greater recognition and greater importance in health promotion. Among these actions, public campaigns play an important role in bringing people closer to health information or even preventive procedures, especially when the target audience consists of people who, because of their own means of subsistence, can not have contact with basic attention. Thus, public campaigns are effective means of overcoming the barriers to access of certain groups of the population to health. OBJECTIVES: To assess the presence of actions and habits that constitute preventive measures of hypertension and to analyze the opinion of the participants regarding the importance of carrying out preventive campaigns with the population. METHODOLOGY: A descriptive study carried out in Sobral (CE) with 30 workers from the Central Market of the city. A questionnaire was applied to quantitatively evaluate the presence of habits and actions directly related to preventive measures of hypertension and qualitatively the opinion of the interviewees about the importance of carrying out preventive campaigns with the population. All the participants signed the consent form and free clarification. RESULTS: The search for public health care by these workers is relatively low: around $46 \%$, but when analyzed from a female perspective, $71 \%$ of them seek care.
$70 \%$ of women often check blood pressure against only $60 \%$ of men. It was analyzed in which place these workers usually gaug the pressure: hospitals $5 \%$, Residency $5 \%$, Pharmacies $15 \%$, Campaigns $40 \%$, Health Posts (PSFs) $40 \%$. $100 \%$ of those interviewed said they considered it very important to carry out campaigns. CONCLUSION: We conclude that in the quest for public care, more than half of the men do not seek care. Campaigns correspond to the alternative means of care as effective as PSFs, which is even more relevant due to the profile of the interviewees.

\section{EPIDEMIOLOGICAL PROFILE OF THE MORTALITY BY CUTANEOUS MELANOMA IN BRAZIL FROM 2011 TO 2015}

Pedro Victor Rodrigues Pereira', Gabriel Medina Sobreira de Meneses', Eliane Santana Nogueira', Leandra Rúbia Oliveira Moreira', José Rúther de Moura Pachêco', Maria do Carmo de Carvalho e Martins'.

' Federal University of Piaui

INTRODUCTION: Skin cancer is the most frequent neoplasm in the Brazilian population, representing $30 \%$ of the notified malignant tumours. Its most severe form consists in cutaneous melanoma, which is responsible for about $75 \%$ of the deaths by skin neoplasms, although it has the lowest incidence among notified malignant tumours of this organ. Melanoma is an important public health problem, and requires attention mainly in relation to the predisposing modifiable factors. OBJECTIVE: Evaluate the epidemiological profile of the mortality by skin melanoma in Brazil in the period from 2011 to 2015. METHODS: It is an epidemiological study with a quantitative approach, of the ecological type. The information was obtained on the DATASUS platform, on the TABNET database. The variables of choices for the study were sex, colour/race, age range and geographical region of occurrence. For analysis purposes, the results were expressed in average mortality rate for the years 2011 to 2015 (number of deaths / 100,000 individuals). The colours pardo and black were grouped in the colour black, considering the criteria of the Brazilian Institute of Geography and Statistics (IBGE). RESULTS: In the period from 2011 to 2015 , a total of 7.947 deaths were registered for melanoma in Brazil, with ascendant progression in the considered years. The mortality rate was 0,92 among men carriers of the disease and 0,66 of the ill female population (1,39 times higher in males). When it comes to colour/race, the death rate for white patients was 1.35 , six times higher than for black patients $(0,23)$. The proportion of deaths increased with advancing age, reaching 10 deaths for every 100,000 in people over the age of 80 . Finally, the geographic distribution of deaths due to melanoma is higher in the South region $(1,85)$ and lower in the Northeast and North regions, with rates of 0.37 and 0.21 , respectively. CONCLUSION: Mortality due to cutaneous melanoma in the country in the years 2011 to 2015 was higher in males, white, elderly, and residents of the South. This epidemiological profile is in concordance with some of the factors recognized in other studies as factors associated with greater chances of developing skin cancer. These findings evidenced the need for protective measures and the use of photoprotectors for the prevention of skin cancer, as well as actions aimed at the early diagnosis and reduction of cutaneous melanoma mortality.

\section{EPIDEMIOLOGICAL ASPECTS OF HANSEN'S DISEASE IN THE NORTHEAST FROM 2010 TO 2015}

Pedro Victor Rodrigues Pereira', Gabriel Medina Sobreira de Meneses' ${ }^{1}$ Zayla Adeilde Aguiar de Brito', Ana Angélica Luz Pereira', Eliane Santana Nogueira', Maria do Carmo de Carvalho e Martins'.

'Federal University of Piaui

INTRODUCTION: Known as the disease of poverty, Hansen's disease has in Brazil its second country in the world with the highest number of carriers of the illness, where it's classified as a neglected tropical disease, according to the World Health organization. The Northeast region, in the other hand, is annually highlighted for presenting the highest numbers when it comes to the problem, what makes evident the association of the disease with local socio-economic conditions and its reflections on the 
quality of life of the population. OBJECTIVE: Evaluate the epidemiological elements of Hansen's disease in the Brazilian Northeast in the period from 2010 to 2015. METHODS: It is an epidemiological time series study, retrospective and documental. The analysed values come from Brazil's Information System for Notifiable Diseases (SINAN), in addition to references from the Brazilian Institute of Geography and Statistics. The collected data belong to the period from 2010 to 2015. As variable of choices, it was chosen by sex, age range, and geographical state of occurrence. The results were described in average incidence rate for the period, in a ratio between the number of people affected per 100,000 people. RESULTS: Between 2010 and 2015, 196.682 new cases of Hansen's disease were notified in Brazil, with the Northeast covering $83,348(42.38 \%)$ of this sum. Having this region as a focus, it is estimated that the incidence rate for the male population was 27.08 , a value that is only $18 \%$ higher in relation to the female population $(23,03)$; Nevertheless, the number of deaths of ill men was almost 3 times greater than the number for women with the disease. Furthermore, the incidence of Hansen's disease among Northeast people is progressively increasing with the increase in the age group, reaching a peak in 65 to 79 years $(59,35)$. The geographic distribution of the disease is influenced by the local socio-economic development, considering that the highest rates were found in the states of Maranhão and Piauí, with respective values of 56.83 and 36.47; At the other end, Rio Grande do Norte presented the lowest rate of the region: 8,22. CONCLUSION: The epidemiological profile of the carriers of Hansen's disease in the Northeast is characterized by male individuals, elders and inhabitants of states with lower human development. The survey of these epidemiological aspects is useful for the organization of measures that improve hygiene conditions and actions that promote early diagnosis and reduction of deaths by the disease, especially in the most vulnerable states.

31. CHOLECYSTECTOMY - EPIDEMIOLOGICAL EVALUATION OF 3280 PATIENTS OPERATED IN REFERENCE HOSPITAL IN NORTHEAST OF BRAZIL

Eduardo Salmito Soares Pinto', Leonardo Rodrigues de Sá2, Welligton Ribeiro Figueiredo3, Taís de Sousa Campos4, Iana de Sousa Campos33, José Pereira do Rego Neto 4 .

Uninovafapi University Center, ${ }^{2}$ HGV - State University of Piauí, 3 Facid Devry, 4 State University of Maranhão

INTRODUCTION: Among the most common gastrointestinal diseases, cholelithiasis mostly affects young, healthy and asymptomatic patients, reaching a prevalence of about $35 \%$ in the general population. Nowadays, videolaparoscopic cholecystectomy is the standard procedure indicated for gallbladder diseases, mainly including cholelithiasis; since its introduction, has dramatically reduced postoperative pain, length of hospital stays and recovery time, also reaching extremely low mortality rate. OBJECTIVE: States the epidemiological characteristics of patients who had undergone elective cholecystectomy in reference hospital, located in northeast of Brazil. METHODOLOGY: It was a retrospective and quantitative study, approved by the Ethics Committee of the hospital. The data were obtained by review of electronic medical records of patients who had undergone cholecystectomy (the type of surgery - open or laparoscopic cholecystectomy - was not discerned) since January/2008 to March/2016 in reference hospital of Piauí, state located in northeast of Brazil. The variables were: age, sex, origin, length of hospital stays and postoperative mortality. RESULTS: The final sample resulted in 3280 patients. $81,6 \%$ of them were female, while $18,4 \%$, male. The mean age was 46,13 years ( 44,8 was the female mean, and 51 , the male mean). The majority of patients $(76,1 \%)$ were between 18 and 60 years old. About the origin, most of them $(66,5 \%)$ came from the capital of the State of Piauí, while the rest, from the interior region of the State in question $(31,35 \%)$ or from other States $(2,2 \%)$. About the hospital stays, $57,8 \%$ stayed in the hospital for 02 days, while $41,9 \%$ remained hospitalized for 03 or more days; 263 of these had hospital stays of at least 07 days or more (average length of 14-15 days), with the female sex representing $68,8 \%$ of them. The postoperative mortality rate was $0,24 \%$ (08 deaths), of which 06 were female, 05 had more than 60 years old, and all of them came from interior regions of the State of Piauí. CONCLUSION: In study, elective cholecystectomy performed in reference hospital was surgery mainly destinated to female patients with age ranging from 18 to 60 years old, that came from the capital of the State of Piauí, demanding an average hospital stays of 03 days, with a very low postoperative mortality rate.

\section{INCISIONAL HERNIA - EPIDEMIOLOGICAL EVALUATION OF 461 PATIENTS OPERATED IN REFERENCE HOSPITAL IN NORTHEAST} OF BRAZIL

Eduardo Salmito Soares Pinto', Iana de Sousa Campos's, Taís de Sousa Campos ${ }^{4}$, losé Pereira do Rego Neto ${ }^{4}$ Leonardo Rodrigues de Sáz, Welligton Ribeiro Figueiredo3. 1 Uninovafapi University Center, ${ }^{2}$ HGV - State University of Piaui, ${ }^{3}$ Facid Devry, ${ }^{4}$ State University of Maranhão

INTRODUCTION: Incisional hernia is the bulge that occurs under the incision (scar) of a previous surgery. Its incidence and prevalence depend on various factors, occurring mainly in obese patients, and those submitted to gynecological, obstetrical and urgent surgeries. Its occurrence has been reported in up to $10 \%$ of abdominal surgical procedures, caused by circumstances as tension excess on scar and inappropriate cicatrization of abdominal wall. OBJECTIVE: States the epidemiological characteristics of patients who had undergone elective incisional hernioplasty in reference hospital, located in northeast of Brazil. METHODOLOGY: It was a retrospective and quantitative study, approved by the Ethics Committee of the hospital. The data were obtained by review of electronic medical records of patients who had undergone incisional hernioplasty since 2008 to 2016 in reference hospital of Piauí, state located in northeast of Brazil. The variables were: age, sex, origin, length of hospital stays and postoperative mortality. RESULTS: The final sample resulted in 461 patients. $67,9 \%$ of them were female, while $32,1 \%$, male. The majority of patients $(67 \%)$ were between 18 and 60 years old, while $33 \%$ were above 60 years old. About the origin, most of them (97,18\%) came from the State of Piaui, while the rest, from other States. About the hospital stays, $85,46 \%$ stayed in the hospital between 01 and 05 days, while the rest remained hospitalized between 06 and 10 days $(11,06 \%)$ or more than 10 days $(3,04 \%)$. The postoperative mortality rate was $0,43 \%$ (02 deaths). CONCLUSION: In study, elective incisional hernioplasty performed in reference hospital was surgery mainly destinated to female patients with age ranging from 18 to 60 years old, that came from the State of Piauí, demanding an average hospital stays of up to 05 days, with a very low postoperative mortality rate.

\section{INGUINAL HERNIA - EPIDEMIOLOGICAL EVALUATION OF 1123 PATIENTS OPERATED IN REFERENCE HOSPITAL IN NORTHEAST} OF BRAZIL

Eduardo Salmito Soares Pinto', Iana de Sousa Campos ${ }^{3}$, Taís de Sousa Campos4, Leonardo Rodrigues de Sáa Welligton Ribeiro Figueiredo ${ }^{3}$, José Pereira do Rego Neto ${ }^{4}$. 1 Uninovafapi University Center. ${ }^{2}$ HCV - State University of Piaui, Facid Devry, 4 State University of Maranhão

INTRODUCTION: It is estimated that $5 \%$ of global population will be affected by some type of hernia of the abdominal wall, as the inguinal hernia is the most prevalent type ( $75 \%$ of all hernias); male sex and age are the main factors that increase the tota prevalence, complication risk and hospitalization. The fragility of abdominal wall and the increase in abdominal pressure have been considered key elements in its etiopathogenesis. OBJECTIVE: States the epidemiological characteristics of patients who had undergone elective inguinal hernioplasty in reference hospital, located in northeast of Brazil. METHODOLOGY: It was a retrospective and quantitative study, approved by the Ethics Committee of the hospital. The data were obtained by review of electronic medical records of patients who had undergone inguinal hernioplasty (the type of surgery - with or without mesh - was not discerned) since June/2008 to March/2016 in reference hospital of Piauí, state located in northeast of Brazil. The variables were: age, sex, origin, length of hospital stays and postoperative mortality. RESULTS: The final sample resulted in 1123 patients. $88 \%$ of them were male, while $12 \%$, female. The majority of patients $(58 \%)$ were between 18 and 60 years old, while $40 \%$ were above 60 years old. About the 
origin, most of them $(75 \%)$ came from the capital of the State of Piaui, while the rest, from the interior region of the State in question $(23 \%)$ or from other States $(2 \%)$. About the hospital stays, $69 \%$ stayed in the hospital for 02 days, while $31 \%$ remained hospitalized for 03 days $(19 \%)$ or more $(12 \%)$. The postoperative mortality rate was $0,089 \%$ (01 death - female). CONCLUSION: In study, elective inguinal hernioplasty performed in reference hospital was surgery mainly destinated to male patients with age ranging from 18 to 60 years old, that came from the capital of the State of Piauí, demanding an average hospital stays of 03 days, with a very low postoperative mortality rate.

\section{SPLENECTOMY - EPIDEMIOLOGICAL EVALUATION OF 40 PATIENTS OPERATED IN REFERENCE HOSPITAL IN NORTHEAST OF BRAZIL}

Eduardo Salmito Soares Pinto', Iana de Sousa Campos'3, Taís de Sousa Campos ${ }^{4}$, José Pereira do Rego Neto4, Leonardo Rodrigues de Sáz ${ }^{2}$ Welligton Ribeiro Figueiredo ${ }^{3}$. 1 Uninovafapi University Center, ${ }^{2}$ HGV - State University of Piaui, 3 Facid Devry, ${ }^{4}$ State University of Maranhão

INTRODUCTION: At the beginning of fetal development, the spleen performs a well-known hematopoietic function and, in adult phase, is responsible primarily for destroying old and affect red blood cells, also contributing to the control of infections and normal functioning of immune system. The main reason for the indication of splenectomy is hematological, immunological and oncological diseases, representing $54 \%$ of all indications, followed by trauma, $16 \%$, and other conditions, but there are divergences about the clinical indications among the main bibliographical sources. OBJECTIVE: States the epidemiological characteristics of patients who had undergone elective splenectomy in reference hospital, located in northeast of Brazil. METHODOLOGY: It was a retrospective and quantitative study, approved by the Ethics Committee of the hospital. The data were obtained by review of electronic medical records of patients who had undergone elective splenectomy since June/2008 to January/2016 in reference hospital of Piauí, state located in northeast of Brazil. The variables were: age, sex, origin, etiology, length of hospital stays and postoperative mortality. RESULTS: The final sample resulted in 40 patients. $55 \%$ of them were male, while $45 \%$, female. The majority of patients $(70 \%)$ were between 18 and 60 years old, while $23 \%$ were above 60 years old. About the origin, most of them (50\%) came from the capital of the State of Piaui, while the rest, from the interior region of the State in question $(43 \%)$ or from other States (7\%). About the etiology, trauma and blood cells/hematopoietic organs conditions were the main causes of surgery $(15 \%$ each); in addition, autoimmune hemolytic anemia, hypersplenism, splenic abscess are included in other causes. About the hospital stays, $52,5 \%$ stayed in the hospital between 03 and 06 days, while 32,5\% remained hospitalized between 07 and 14 days, and $15 \%$ had a length higher than 15 days. The postoperative mortality rate was $2,5 \%$. CONCLUSION: In study, elective splenectomy performed in reference hospital was surgery mainly destinated to young patients with age under 60 years old, with diversified etiology, that came from the capital of the State of Piauí, demanding an average hospital stays of 07 days, with a low postoperative mortality rate.

\section{UMBILICAL HERNIA - EPIDEMIOLOGICAL EVALUATION OF 436 PATIENTS OPERATED IN REFERENCE HOSPITAL IN NORTHEAST OF BRAZIL}

Eduardo Salmito Soares Pinto', Leonardo Rodrigues de Sáz, Welligton Ribeiro Figueiredo30, José Pereira do Rego Neto ${ }^{4}$, Taís de Sousa Campos4, Iana de Sousa Campos3.

1 Uninovafapi University Center, ${ }^{2} \mathrm{HGV}$ - State University of Piaui, 3 Facid Devry, 4 State University of Maranhão

INTRODUCTION: Umbilical hernia in adults are commonly acquired through a continuous increase of intra-abdominal pressure in physiological or pathological conditions, as occurs during laborious activities, pregnancy, obesity, ascitis, cronical cough, constipation, etc. This disease has low rate of complications (incarcerated or strangulated hernias), which most frequently occurs when associated with another disease or condition, like ascitis. Usually, patients that have symptomatic or volumous umbilical hernia must be submitted to a surgical procedure, despite there is no consensus on which method to use - with or without mesh. OBJECTIVE: States the epidemiological characteristics of patients who had undergone elective umbilical hernioplasty in reference hospital, located in northeast of Brazil. METHODOLOGY: It was a retrospective and quantitative study, approved by the Ethics Committee of the hospital. The data were obtained by review of electronic medical records of patients who had undergone elective umbilical hernioplasty (the type of surgery - with or without mesh - was not discerned) since May/2008 to March/2016 in reference hospital of Piauí, state located in northeast of Brazil. The variables were: age, sex, origin, length of hospital stays and postoperative mortality. RESULTS: The final sample resulted in 436 patients. $58 \%$ of them were female, while $42 \%$, male. The majority of patients $(85 \%)$ were between 18 and 60 years old. The mean age was 36,78 years. About the origin, most of them ( $75 \%$ ) came from the capital of the State of Piauí, while the rest, from the interior region of the State in question $(24 \%)$ or from other States $(1 \%)$. About the hospital stays, $87 \%$ stayed in the hospital for 02 days, while $13 \%$ remained hospitalized for 03 or more days. The postoperative mortality rate was nil. CONCLUSION: In study, elective umbilical hernioplasty performed in reference hospital was surgery mainly destinated to female patients with age ranging from 18 to 60 years old, that came from the capital of the State of Piauí, demanding an average hospital stays of 03 days, with a nil postoperative mortality rate.

\section{HEALTH ACTION FOR FAMILIES OF CHILDREN WITH RARE GENETIC DISEASES}

Amanda Karoliny Meneses Resende'; Regilane Silva Barros².

'State University of Piauí, ${ }^{2}$ Federal University of Piauí

INTRODUCTION: Genetic diseases are still an important cause of infant mortality in Brazil. The biggest challenge for patients and their families is the lack of knowledge and, above all, investments in this sector. If effective measures are not taken, early diagnosis and treatment will remain difficult to achieve, due to the specificity of tests and high-cost drugs, such as those necessary for the treatment of Gaucher, Mucopolysaccharidosis and atypical hemolytic uremic syndrome. OBJECTIVE: To describe an experience about a health action for families of children with rare genetic diseases, in which education was sought to promote the exchange of technical and popular knowledge. METHODS: This is a descriptive study of the type of experience report, experienced by nursing students during a mandatory internship in February 2017, at a referral hospital in Teresina, Piaui state, Brazil. In which came the idea of creating the event entitled "I Seminar of the world day of rare diseases in Teresina" to strengthen the dissemination of information in this area. Thus, a song was written and it contemplated the rights of the children in the Unified Health System and the symptomatology of the illness. Subsequently, there was a dramatization and discussion of the following themes: definition of Gaucher, Mucopolysaccharidosis and atypical Hemolytic Uremic Syndrome, clinical manifestations, diagnosis and treatment of these diseases. In the end, a motivational talk with the testimony of a patient with Gaucher brought positive reflections on overcoming and quality of life. RESULTS: 13 families of children with rare diseases and their children participated. It was possible to assess the needs of this audience that needs special attention. All families had insufficient knowledge about the disease, symptomatology and therapeutic complexity. From the experience it was evident that the activity brought a new look for the promotion of the quality of life, since it provided well-being, learning, dignity, strengthening of autonomy and bond, increasing respect and trust in the team. CONCLUSION: Health action is a good strategy to demystify the disease, provide knowledge exchange and achieve excellence in the quality of care provided. Although there are still many gaps in such practices, this contributes to many barriers to the advancement of care in these diseases in Brazil. 


\section{THE PATH TAKEN BY FAMILIES TO THE DIAGNOSIS OF MUCOPOLISSACARIDOSE}

Amanda Karoliny Meneses Resende'; Regilane Silva Barros ${ }^{2}$.

'State University of Piaui, ${ }^{2}$ Federal University of Piauí

INTRODUCTION: Mucopolysaccharidoses are a group of rare diseases caused by the deficiency of enzymes involved in the catabolism of glycosaminoglycans. According to the clinical and biochemical characteristics it is classified into 7 distinct types, but which have similarities between them. Although the onset of symptoms often occurs in infancy, studies indicate the occurrence of underdiagnosis and a higher average age at the diagnosis of these patients, which impedes the early access of families to genetic counseling and specific treatment. OBJECTIVE: To describe an experience on the path taken by families until the diagnosis of mucopolysaccharidosis. METHODS: This is an experience report, carried out by nursing students, during a voluntary internship from February to May 2017, at a public referral children's hospita in the city of Teresina, Piaui state, Brazil. In which through the nursing consultations, all relevant information regarding the path taken by families until the diagnosis of the disease was collected. RESULTS: Three to twenty years old children were examined, in which six had already been diagnosed with the diseases corresponding to types $\mathrm{I}$ and $\mathrm{II}$, and two through the nursing consultation, an unexpected diagnosis emerged, confirmed later. It was verified that, from the beginning of the symptomatology, despite the evident clinical manifestations and the evaluations by different health professionals, there were many difficulties encountered in diagnosing the underlying pathology. This fact probably demonstrates the restricted knowledge of the Brazilian professionals about mucopolysaccharidosis. Other relevant information was the surgical interventions performed before the diagnosis of the disease, similar to that described in the literature, resulting in an increased risk of mortality. Through the experience it was evident the need to expand the scientific discussions about this disease, to extend early diagnosis and treatment, avoiding unnecessary complications. CONCLUSION: Thus, the difficulty in finding the diagnosis of mucopolysaccharidosis is perceived. This makes it difficult to obtain treatment in a timely manner and contributes to the high mortality associated with worsening clinical manifestations. It is hoped that this study encourages further research, because despite the small incidence of the syndrome, this causes great family distress in the search for diagnosis and treatment.

38.

ACCIDENTS BY SPECIAL ANIMALS WITH CHILDREN IN THE STATE OF MARANHÃO, BETWEEN THE YEARS OF 2007 AND 2015.

José Pereira do Rego Neto', Taís de Sousa Campos', Suzanne Vasconcelos Alves', Luciano André Assunção Barros $^{2}$

' State University of Maranhão, ${ }^{2}$ Federal University of Piauí

INTRODUCTION: Venomous animals are those that produce or modify poison and have structures capable of inoculating it in its prey or predator. Due to its tropical climate and diverse fauna, Brazil has several species of these animals, which constitute a common cause of accidents, occurring numerous cases in Maranhão. The situation is aggravated by putting at risk the health of children, who are routinely victims of accidents by venomous animals. OBJECTIVES: To analyze the epidemiological aspects of accidents of venomous animals in children up to 9 years of age, in the state of Maranhão, between 2007 and 2015. METHODS: A descriptive study with a quantitative analysis of data recorded in the SINAN Notification Disorders) on accidents involving venomous animals in the state of Maranhão, in children up to 9 years old, from January 2007 to December 2015. The aspects analyzed were: sex, type of accident, time elapsed from accident to care, Classification and evolution of cases. RESULTS: In the analyzed period, 18142 cases of accidents involving venomous animals were reported, of which $1784(9.8 \%)$ occurred with children aged 0 to 9 years. of the cases evaluated, $65.75 \%$ were male and $34.25 \%$ female. It was observed that snakes and scorpions are the major cause of accidents, corresponding respectively to $66.70 \%$ and
$16.70 \%$. The interval from 1 to 3 hours $(32.62 \%$ ) and 0 to 1 hou $(28.19 \%)$ prevailed. In the final classification there was a predominance of mild $(68.27 \%$ ) and moderate $(20.51 \%)$. About the evolution of the cases it was noted that $82.79 \%$ resulted in cure. CONCLUSION: The incidence of accidents by venomous animals in children in the State of Maranhão is significant, affecting mainly males. The prevalence of mild accidents and high percentage of cure are positive statistics for children's health, however, there is still great danger represented mainly by contact with snakes and scorpions. In addition, the time between the accident and the care prevails from 1 to 3 hours, which should be reduced for better treatment and evolution of the cases. In this scenario, it is imperative to integrate the community with local health teams in order to raise awareness about prevention and care measures for children.

39. THE AUTOMEDICATION PRACTICE AGAINST ARBOVIROSIS SYMPTOMS IN PATIENTS OF THE CITY OF CAXIAS-MA

José Pereira do Rego Neto', Taís de Sousa Campos', Louise da Mota Dutra', Luciano André Assunção Barros².

1 State University of Maranhão, ${ }^{2}$ Federal University of Piauí

INTRODUCTION: Arbovirosis are named in this way because their replication cycle occurs in insects, and can be transmitted to humans and other animals by the bite of hematophagous arthropods. There is no specific treatment for classical arboviruses. Rest and heavy fluid intake are important behaviors that aim at the best prognosis of the patient, in addition to symptomatic patients prescribed with medical advice. Although this practice often obtains favorable results (improvement of symptoms or resolution of the health problem), in other cases it may cause harm to the health of the individual (exogenous intoxication, drug interactions, adverse reactions and masking of other health problems) OBJECTIVES: To evaluate the habit of self-medication with allopathic or natural remedies and its aggravations regarding symptomatology in patients with arbovirosis. METHODS: The study was carried out in the municipality of Caxias-MA between August 2016 and December 2016. Data were collected from 184 adult patients aged 18-59 years, with clinical and epidemiological symptomatology suggestive of arboviruses treated at the Unidade pronto Assistência (UPA) who signed a consent form for the disclosure of such data. The following criteria were addressed: symptoms, search for medical care or another professional, therapy used and reason for self-medication. RESULTS: Approximately $64 \%$ of respondents received information from nonmedical or lay people. The drugs used by the patients were: dipyrone (54.35\%), paracetamol (43.48\%) and acetylsalicylic acid $(2.17 \%)$. The use of natural treatments with teas, herbs and "bottled" was confirmed by $27.17 \%$ of the participants. $40 \%$ of the patients reported some type of discomfort after the use of selfmedication. The most frequent complaints were: pruritus, edema, parageusia and abdominal pain. Among the reasons that influenced self-medication, the most cited were: ease of purchase and lack of access to health care. CONCLUSIONS: Thus, it was found that self-medication is a common practice among users served at the UPA-Caxias as a mechanism to overcome the deficiencies of the service and to be more practical to the patient. Because it is a potentially harmful method to health, it deserves special attention from the authorities regarding awareness. These data can therefore be used in the definition of strategies aimed at promoting the rational use of medicines.

\section{THE OCCURRENCE OF OUTBREAKS OF CHAGAS' DISEASE IN THE AMAZON REGION BY ORAL TRANSMISSION BETWEEN 2007-} 2014

Taís de Sousa Campos $^{2}$, José Pereira do Rego Neto² Jefferson Feques Ferreira Costa ${ }^{2}$, Iana de Sousa Campos', Suzanne Vasconcelos Alves², Mônica Cristina Melo Santos Gomes ${ }^{3}$.

${ }^{1}$ Facid Devry, ${ }^{2}$ State University of Maranhão, ${ }^{3}$ State University of Paraíba

INTRODUCTION: Chagas disease is an anthropozoonosis caused by the flagellate protozoan Trypanosoma cruzi and presents a 
biphasic clinical course, with an acute phase that can progress to chronic. In recent years, outbreaks of Acute Chagas Disease (ACD) in the Amazon region have been frequent, mainly due to oral transmission, which implies the need for surveillance and control strategies, in line with the current epidemiological pattern. OBJECTIVES: To characterize the outbreaks of ACD, which had oral transmission, occurred in the years 2007 to 2014 in the Amazon region. METHODS: This is a quantitative epidemiological study, based on information on cases of Chagas' disease in the Amazon region (Acre, Amapá, Amazonas, Pará, Rondônia, Roraima, Tocantins and part of the states of Mato Grosso and Maranhão) In the SINAN (Information System of Notification Diseases), in addition to technical documents of the Ministry of Health. It is designated as an outbreak the registration of two or more confirmed cases of ACDs exposed to the same probable source of infection in the same period of time, In a specific geographic area. Only cases that had oral transmission were studied. For analysis and organization of the data in tables and graphs, Microsoft Office Excel was used. RESULTS: It was verified the occurrence of 80 outbreaks of ACD by oral transmission in the Amazon region. It was noted that the state of Para recorded 60 cases $(80 \%)$ and the state of Amapá 10 cases (12.5\%). In the cities of Belém (PA), Abaetetuba (PA) and Macapá (AP), a large incidence of outbreaks was observed, representing $27.5 \%$ of the total. The probable source of infection was the ingestion of foods contaminated with T. cruzi, among them: açai, bacaba, jaci (coquinho), juice of cane and babassu palm heart. CONCLUSION: With the aforementioned data it is evident that there is a high incidence of $A C D$ by oral transmission in the Amazon region, mainly in the states of Pará and Amapá. In addition, the described outbreaks had as a common factor the ingestion of foods contaminated with T.cruzi, consumed in natura. In this way, it becomes essential the action of the Sanitary Surveillance, in order to carry out hygienic-sanitary conducts to reduce and prevent new cases. In addition, greater control and investigation of ACD reporting is essential to control and prevent outbreaks.

\section{1.}

\section{CLINICAL AND EPIDEMIOLOGICAL PROFILE OF TUBERCULOSIS / HIV COINFECTION IN THE STATE OF MARANHÃO IN THE LAST 10 YEARS}

Taís de Sousa Campos', José Pereira do Rego Neto', Louise da Mota Dutra', Mônica Cristina Melo Santos Gomes². 'State University of Maranhão, ${ }^{2}$ State University of Paraíba

INTRODUCTION: The human immunodeficiency virus (HIV) has contributed to the increase in the number of cases of tuberculosis (TB). Thus, TB control in the world is not yet a reality, especially in low-income populations, since the HIV / TB association is still the leading cause of death in this population. In Maranhão, there are favorable conditions for maintaining high rates of TB / HIV coinfection prevalence, due to poor population conglomerates and the very disruption of public health services. OBJECTIVES: To map an epidemiological profile of patients with HIV / TB coinfection reported in the state of Maranhão in the last 10 years. METHODS: Quantitative research was carried out through a retrospective epidemiological study from 2006 to 2016, using as sources of information the cases of HIV / TB coinfection reported in the SINAN (Information System for Notifiable Diseases). Only cases with the HIV condition were studied. The following aspects were evaluated: gender, age, forms, schooling, associated diseases and outcomes. The data was exported to Microsoft Excel software and analyzed later. RESULTS: It was found that $6.02 \%$ of patients diagnosed with tuberculosis were tested positive for HIV. Among patients with HIV / TB coinfection, $74.42 \%$ of the cases were male and $25.58 \%$ female. The prevalent age range was $20-39$ years (59.55\%) and the majority of the patients had incomplete elementary school education $(49.42 \%)$. The clinical forms presented were: $80.19 \%$ exclusively pulmonary, $18.08 \%$ extrapulmonary and $1.73 \%$ both presentations. The most common forms were: peripheral ganglion $(8.9 \%)$, pleural $(5.51 \%)$ and miliary $(1.4 \%)$. Associated diseases were identified: alcoholism $(14.17 \%),(3.84 \%)$ and diabetes $(4.74 \%)$. The dropout rate was $13.78 \%, 51.15 \%$ of cases evolved to cure, $9.10 \%$ resulted in death from tuberculosis and $6.60 \%$ in death from other causes. CONCLUSION: Based on the data analyzed, the substantial HIV / TB association is evident, in which the most affected people are young males with low educational level. In addition, the occurrence of variable clinical manifestations of $T B$, the high dropout rate and the low cure rate identify the ineffective care of the TB / HIV coinfected patient in the state of Maranhão.

\section{ANALYSIS OF THE EPIDEMIOLOGICAL PROFILE OF SUICIDE TRIALS FROM EXOTIC INTOXICATION IN PIAUÍ BETWEEN 2010} AND 2015

Taís de Sousa Campos', José Pereira do Rego Neto', Iana de Sousa Campos33, Mônica Cristina Melo Santos Comes².

'State University of Maranhão, 2 State University of Paraiba, 3 Facid Devry

INTRODUCTION: In recent decades there has been a significant increase in suicide rates worldwide. Exogenous intoxications are one of the three main means used in these suicide attempts, mainly because of the advances in science that make available to the population an increasing number of potentially toxic products to the human body. Thus, this tool represents a serious public health problem and needs to be analyzed in the light of epidemiology in the State of Piauí OBJECTIVES: In order to improve the quality of information regarding the suicide attempt due to exogenous intoxication, the epidemiological profile of the patients Meeting these criteria from January 2010 to December 2015 in the State of Piauí; METHODS: Quantitative research was carried out through a retrospective epidemiological study from 2010 to 2015 , using exogenous cases of intoxication reported in SINAN (Information System for Notifiable Diseases) as sources of information. Only the cases with the circumstance of intoxication was suicide attempt were analyzed. The following aspects were evaluated: sex, age, schooling, toxic agent used and evolution. RESULTS: 1313 cases of exogenous poisoning suicide were reported between 2010 and 2015 . Of these, $73.57 \%$ were female and $26.43 \%$ were male. The prevalent age is below 60 years, with a higher incidence between 20 and 39 years $(55.29 \%)$. The most frequently used toxic drugs were: drugs $(66 \%)$, high-school education $(11 \%)$ and high school $(10 \%)$, The most frequent evolution was a cure without sequelae ( $78.67 \%)$. CONCLUSION: From the analysis of the data, it is inferred that the majority of the cases of rodenticide $(13 \%)$ and products of home use $(5.4 \%)$. Attempted suicide were committed by young and female people, mainly by the use of drugs. In addition, it is observed that the clinical evolution is favorable in most cases, with establishment of cure without sequelae. In this panorama, it is verified that the easy access to medicines and other toxic agents that make possible the attempt of intoxication suicide. Thus, it is essential to establish strategies that prevent the emergence of new cases and recidivism.

\section{CROTALIC ACCIDENT IN A 7-YEAR-OLD CHILD}

José Pereira do Rego Neto', Taís de Sousa Campos', Louise da Mota Dutra', Eduardo Salmito Soares Pinto ${ }^{2}$

${ }^{1}$ State University of Maranhão, ${ }^{2}$ Uninovafapi University Center

INTRODUCTION: Snakebite accidents represent a serious public health problem in tropical countries due to the frequency with which they occur and the morbidity and mortality they cause. Serpents of the genus Crotalus are popularly known as Rattlesnakes and their main feature is the presence of rattle in the tail. Crotalic venous has neurotoxic, coagulant and myotoxic systemic activity. The aim of this study was to analyze the changes caused by a crotalic accident in a 7-year-old child; CASE REPORT: J.P.S.L., male, 7 years old, reported being in the backyard when he suffered an accident due to stinging of venomous animal, identified by the companion as "Cascavel" (Crotalus). The patient was bitten in the right lower limb (MID) and taken to immediate care in the city of origin, where he received 2 units of Anticrotalic Serum (SAC) that the unit had at the time, then referred to the CAXIAS- BAD. At $20: 00$ hrs on 02/14/2017, 4 hours after the incident, he reported minor pain at the site of the bite, with edema and paresthesia. There was a decrease in the general state compared to the first care, with malaise, nausea, vomiting, sweating, headache, prostration and drowsiness. He was found with myasthenic facies, bilateral palpebral ptosis and cloudy urine. An additional 8 ampoules of CSA, hydration and symptomatic 
treatment were prescribed. Coagulation time (CT), creatinine, glutamic-oxalacetic transaminase, glutamic-pyruvic transaminase, creatine phosphokinase (CPK) and lactic dehydrogenase were requested. In the result, slight increase in $\mathrm{TC}=10 \mathrm{~min}(\mathrm{vr}=3$ to $9 \mathrm{~min})$ and $\mathrm{CPK}=180 \mathrm{U} / \mathrm{L}(\mathrm{vr}=55-170 \mathrm{U} / \mathrm{I})$, other normal exams. The morning after the accident, he was asymptomatic, with ptosis in his left eye. On 02/16/2017 the same exams were performed and the normalization of the same was noted. He remained asymptomatic until discharged on 17/02/17. FINAL CONSIDERATIONS: The agreement between the reported case and the literature data, both regarding local changes and laboratory abnormalities, was observed, Is a classic crotalic accident, where the venom has a greater systemic action than local. In the case reported, the delay in the correct prescription of doses of serum may have contributed to the aggravation of the patient's condition, so emergency units need to keep stock of antiofidic sera to contain the acute clinical / laboratory progression of the cases.

\section{MIRIZZI'S SYNDROME}

Isadora Maria Gonçalo de Oliveira', Beatriz Carvalho Neiva', Juliana de Sa Pires Carvalho', Josúe Silva Coêlho de Oliveira², Fabiana Brito Campelo', Jefferson Clerke Lopes Campelo3.

' Facid Devry, ${ }^{2}$ Federal University of Piauí, 3 São Marcos Hospital

INTRODUCTION: Mirizzi's syndrome consists of an extrinsic obstruction of the biliary tract due to the presence of a calculus in the cystic duct or in the infundibulum of the gallbladder, triggering an inflammatory process and common bile duct's spasm, which will lead to a clinical condition of obstructive icterus. It is present in about 0.7 to $2 \%$ of patients with biliary lithiasis and occurs mainly in women over 40 years. The present report aims to describe the treatment of a patient with this rare syndrome. CASE REPORT: M.V.A.L, female, born on 09/09/1963, 84kg, 1,56m, BMI of $34,5 \mathrm{~kg} / \mathrm{m} 2$. Patient admitted to a private hospital in Teresina with a history of epigastric pain. She was anicteric, afebrile, and referred intolerance to fatty foods. She underwent cholangioresonance, in which she was diagnosed with Mirizzi's Syndrome grade II and no calculus in the common bile duct. She underwent laparoscopic cholecystectomy without cholangiography, during which acute chronic cholecystitis became evident. Adhesions were lysed, as the omentum, duodenum and part of the small gastric curvature were blocking the gallbladder. Due to the difficulty in identifying the Callot triangle, a deepcystic dissection was chosen. In the inventory of the abdominal cavity, the vesicular infundibulum was swollen, with thickened walls and a stuck calculus so that one-third of its surface was eroding the common bile duct's wall. It was also identified area of necrosis and purulent secretion between the hepatic bed and the gallbladder. Due to the choledochal raffia and the possibility of fistula formation, a suction drain was placed in the abdominal cavity, which was removed on the fifth postoperative day. After cholecystectomy, the patient progressed steadily, being discharged three days after the surgical procedure. FINAL CONSIDERATIONS: This report shows the importance of Mirizzi Syndrome as differential diagnosis in patients with biliary lithiasis.

\section{RETROSPECTIVE ANALYSIS OF 3 CASES OF BREAST CANCER IN PATIENTS AGED LESS THAN 30 YEARS}

Barhbara Brenda Dias Garcez', Sabas Carlos Vieira², Aila Batista Rodrigues33, Neiralice da Silva Macêdo4, Victoria Maria Lima Tourinho4, Renan Roberto Rodrigues Reis 5 .

1 State University of Maranhão, ${ }^{2}$ Federal University of Piauí, Uninovafapi University Center, 4 State University of Piauí, 5 Facid Devry

INTRODUCTION: Breast cancer is the most common type of cancer among women worldwide, accounting for $28 \%$ of incidence each year according to INCA data. It can affect male patients, being rare, representing $1 \%$ of the total cases. It is estimated that more than 1 million women are diagnosed each year. Life style interferes with the increase in cancer cases and the main risk factors involved are: woman's age, family history of breast cancer, early menarche, late menopause, age of first birth after 30 years, nulliparity, use of contraceptive hormone, genetic susceptibility, obesity and alcohol.
The recommendation in Brazil is for women between the ages of 50 and 69 to have a mammogram every two years. OBJECTIVES: To analyze 3 cases of breast cancer in women under the age of 30 , considered to be low risk of occurrence. METHODS: The present study was performed through data analysis of a clinic in Teresina evidencing the characteristics of patients affected by breast cancer before 30 years. Data were analyzed based on the following factors: age, gestational history, histological type, alcohol consumption, family history of breast cancer, chemotherapy and radiotherapy, smoking. It was also carried out research of articles on the subject in the databases: scielo, pubmed. RESULTS: Three cases of breast cancer were found in women under the age of 30 years. The ages of the patients were: 24,26 and 29 years. The presence of a history of cancer in only one of the patients, including uterine cancer in the paternal grandmother and a history of prostate cancer, were found: invasive ductal cancer and infiltrating ductal cancer; patients underwent chemotherapy and radiotherapy. Nulliparity was observed in two patients and one was pregnant at diagnosis. CONCLUSION: The incidence of early breast cancer is a reality, which interferes with the quality of life of the affected population and their families, according to INCA the rare type of cancer before age 35. Thus, more research needs to be encouraged for the early detection and offer of better survival and prognosis for these patients, since the evolution of breast cancer appears aggressive in some histological types. In addition, prevention actions on modifiable life factors are necessary.

\section{6. $2^{\circ}$ AND 3 RD DEGREE BURNS IN PSYCHIATRIC PATIENT}

Caio Alcobaça Marcondes', Ilana Lages Rebêlo de Carvalho Rayanne Andresa de Castro Vieira², Bruna Nayanne Gonçalves Barros Leal², Karen Noleto Costa², Sérgio Rogério de Araújo Mendes Filho ${ }^{2}$.

' State University of Piaui, ${ }^{2}$ Uninovafapi University Center

INTRODUCTION: The burns constitute one of the major traumas to which a human being can be exposed, with a metabolic response and intense inflammation that perpetuates and amplifies with the burnt tissue. When deep or widespread, these lesions need immediate medical care, often in specialized units. The healing process, which consists of perfect and coordinated cascading of cellular, molecular and biochemical events, is common in all these wounds, regardless of the agent that caused it, is systemic and dynamic and is directly related to general conditions of the organism. In recent years, there has been a breakthrough in the treatment of burns, resulting in a higher survival rate for people with severe burns. CASE REPORT: Patient F.A.S, 25 years old, male, non-literate. Patient with schizophrenia, in follow-up at a referral psychiatric hospital, victim of physical aggression by iron bars and burn by flames. Referral to emergency hospital evidencing the physical examination, lesions, short-bruises on the face and burns of the 2nd and 3rd grades in the upper right limb, trunk and part of the right flank ( $\mathrm{SQC}=19.5 \%$ according to Lund Browder table). Transferred to Burns Therapy Unit (UTQ), being initially approached with right trunk scarring and curative with $1 \%$ silver sulfadiazine. After 7 days, surgical debridement (of the right upper limb and right lateral region of the trunk) with observation of necrosis of the 5 chirodactyls, and subsequent amputation of the same on the 2oth day of hospitalization (IHD). In a third time, after $66 \mathrm{IHD}$, he underwent graft surgery in the right lateral region of the right trunk, forearm and hand, with good evolution. Hospital discharge after 57 days of last surgical procedure, with graft and donor area with good appearance and good repittalization, with no signs of infection. FINAL CONSIDERATIONS: Although great progress has been made in understanding the processes and phenomena involved in the various stages of tissue repair and at the same time much has been invested in research and development of resources and technologies with the aim of favoring these processes, the incidence and prevalence of burn wounds is still extremely high, impacting on high financial costs and profound social consequences on the patients, which often develop sequels that can lead to loss of limbs and their functions, with consequent withdrawal from work and normal activities. 
47. OUTREACH “TÁ INTERADO? - A DIALOGUE TO PREVENT" - AN APPROACH ABOUT SEXUAL EDUCATION AT THE COMMUNITY OF CAIÇARA (SOBRAL, CE)

Wemerson Magalhães Medeiros', Íkaro lago de Carvalho Cruz', Antônia Rafaelly Fernandes Silva', Maria Carolina Quinderé de Almeida Frota', Camilla Carla do Amaral Rodrigues', Neiline Cavalcante' ? INTA

INTRODUCTION: The vulnerability of young people from suburbs has brought the need to initiate outreaches that make possible to establish a counterpoint to this matter. OBJECTIVE: To promote a discussion environment based on listening and welcoming as well as having the appropriate approach to issues of sexual education. METHODOLOGY: Promotion of a health outreach over sexuality, named "Tá Interado - A Dialogue to Prevent"; in association with a group of residents assisted by Family Health Care Programm alongside with "Youth Station" (a project that promotes events aimed to foment culture at the neighborhood Nova Caiçara). In the first moment, took place an ice breaker called "the pleasures' tree", which contributed to an overview about sexuality. After words, a lecture was given on the subject, clarifying the importance of birth control methods when having sexual relations. Subsequently, there was a moment in which the crowd had opportunity to ask some questions. RESULTS: Around 150 young people from the neighborhood attended the event. On a behind the scenes prospective this high attendance represented the lack of knowledge about basic concepts on this sexual subject. Initially the icebreaker "The Pleasures' Tree" made it possible for the present crowd to be enlightened about the meaning of pleasure. Many felt it hard to express what pleased them and what it meant. Through a round of dialogue, it was made possible to establish a platform for discussions related to sex and to prevention of STDS. An open and less technical conversation was evidenced by a crowd's great participation in the debate, mainly involvement by young people. CONCLUSION: It was noticed that outreaches compose a important health promotion tool to a less assisted portion of Sobral's community. However, more outreaches focused on this topic and other health topics should be targeted to provide guarantee of easy understandable health care to all users.

48. SEDATION, ANALGESIA AND ABSTINENCE SYNDROME IN CHILDREN SUBMITTED TO MECHANICAL VENTILATION IN A PEDIATRIC INTENSIVE THERAPY UNIT

Maylla Moura Araújo', Renanna Najara Veras Rodrigues' July Lima Gomes', Rogério José Xavier', Lorena Keli Lemos Piaulino $\mathrm{Cruz}^{2}$.

' Facid Devry, ${ }^{2}$ Federal University of Piauí

INTRODUCTION: The adverse scenario of the Pediatric Intensive Care Unit, associated with the need for invasive ventilatory support, determines the administration of sedatives and analgesics, which if used excessively and incorrectly, can generate negative repercussions, leading to an increase in the need for ventilatory support duration of hospitalization and increased risk of infection. OBJECTIVE: To describe the use of analgesics and sedatives in children undergoing mechanical ventilation in a Pediatric Intensive Care Unit, verifying the occurrence of withdrawal syndrome. METHODS: An observational, cross-sectional, retrospective, descriptive study was carried out, with a quantitative approach and a secondary analysis of the data. Participants were children admitted to a Pediatric Intensive Care Unit, between July 2014 and June 2015, requiring analgesic and / or sedative therapy in continuous infusion and mechanical ventilation, remaining in the sector for more than 12 hours. The diagnosis of abstinence syndrome was performed by searching for characteristic signs and symptoms in the medical record (recording of the diagnosis or by taking therapeutic measures in this sense, such as the prescription of equivalent weaning drugs). The data were analyzed in the software $R$ version 3.2.2, being considered significant with $p$ values below 0.05 . This research was approved by the Research Ethics Committee of the Faculdade Integral Diferencial (CAAE: 59723616.3.0000.5211). RESULTS: Thirty-one individuals were identified, corresponding to $63 \%$ of in-patients. The most commonly used medications for continuous sedation and analgesia were Midazolam, Ketamine and Fentanyl. These drugs were used in low doses of infusion for a mean time of $11.5 \pm 11.4$ days. Drug tolerance was present in $56.1 \%(n=23)$ of the individuals, and this fact can be related to mean time of use ( $p$ $<0.001)$. Tolerance was also associated with withdrawal syndrome $(p=0.002)$, the latter being presente in 16 patients $(39 \%)$. Prolonged sedoanalgesia was associated with the development of withdrawal syndrome $(p<0.001) .70 \%(n=12)$ of those who used continuous sedation and analgesia for more than 7 days developed abstinence. CONCLUSION: The use of analgesics and sedatives became quite frequent practice. The manifestation of tolerance was related to prolonged sedation and analgesia, culminating in an increase in the total dose of the drugs, inducing the withdrawal syndrome.

\section{ANTIFOSPHOLIPID SYNDROME (APS) WITH FACE ULCER AND HYDROELETROLYTIC DISTURBANCE}

Mateus Dutra Batalha Costa', Mario Sergio Ferreira Santos², Késsia Pachêco Leal', Therezinha Dantas Nobre Neta', Sérgio Augusto de Souza Cavalvante', Francisca Daline dos Santos Silva'.

'State University of Piaui, ${ }^{2}$ Federal University of Piauí

INTRODUCTION: Antiphospholipid syndrome (APS) is characterized by vascular thrombosis and / or gestational morbidity in the presence of antiphospholipid antibodies (APLA). We present a case of discoid lupus (DL) that developed a difficult to control cutaneous ulcer (CU) attributed to APLA. CASE REPORT: female, 62 years old, diagnosis of DL on face and scalp with worsening of the cutaneous condition and appearance of constitutional symptoms. It was presented with deep CU in each hemiface, with deviation of the labial commissure to the right. Hb $6.5 \mathrm{~g} / \mathrm{dL}$, ESR: $140 \mathrm{~mm} / \mathrm{hr}$, ANF, anti-SM, anti-native DNA and anti-Ro unreacted. Anticardiolipin IgG: $9 \mathrm{U} \mathrm{GpL}$ and $\mathrm{IgM}: 40 \mathrm{U} \mathrm{MpL}$; present lupus anticoagulant; anti-Beta-2-Glycoprotein I: 22 and $6.1 \mathrm{U} / \mathrm{mL}$, IgC and IgM respectively. Wide antibiotic therapy, warfarin, ulcer management with alginate, hydroxychloroquine (HCQ) and lowdose corticosteroids were instituted. Weakness, hypotension, sensory impairment, and seizures with decreased sodium, potassium, and magnesium levels, as well as axillary and left basilic veins thrombosis, led to the suspension of warfarin, substituted with heparin. There was general improvement, except for thrombocytopenia under heparin, substituted by rivaroxaban. The CU regressed, although with transient parotid fistula on the right. DISCUSSION: CU is not included in the formal criteria for classification of APS. Although with constitutional symptoms and elevated ESR, the ANF and specific antibodies remained unreactive. Therefore, APS appeared in the context of DL. There are no controlled studies on the management of cutaneous manifestations, especially ulcers. HCQ, warfarin and CU infectious control, including dressings with alginate, proved to be effective except for venous thrombosis. Hydroelectrolytic disorder in the APS / dicoumarinic agent scope, can explain adrenal insufficiency (AI), thrombotic or hemorrhagic, respectively. Absence of hyperkalemia opposes the hypothesis, but they do not totally reject it. We did not use a research protocol for Al. We highlight the role of rivaroxaban in clinical management, along with other interventions. Parotid fistula and facial paralysis were reversed.

\section{NEONATAL GASTRIC DRILL}

Alexandre Gabriel Silva Rego', Liza Maria Sampaio de Brito', Brenda Irla Soares Santos', Bruno Pinheiro Falcão'. 'Federal University of Piauí

INTRODUCTION: Neonatal gastric perforation (NGP) is a rare impairment, very serious and life-threatening condition, presenting mainly in the form of abdominal distension and pneumoperitoneum and requires a surgical approach. Its etiology remains varied and several theories have been proposed to explain its occurrence. Among the causes attributed to NGP are the presence of distal mechanical obstruction of the stomach, ischemic and pharmacological causes. Drilling may also occur iatrogenically, as a result of naso or orogastric tube use, barotrauma due to CPAP (continuous positive airway pressure) or idiopathic. As a matter of extreme importance and severity in the pediatric clinical and surgical environment, a case of neonatal gastric 
perforation with laparotomy correction and suture of the defect is reported. CASE REPORT: Premature asbestos of cesarean delivery of the male gender, 1st twin, Gestational Age equal to 32 weeks, $45 \mathrm{~cm}$ in length, $1935 \mathrm{~g}$ of weight and $33 \mathrm{~cm}$ of cephalic perimeter, referred from Ceneral Hospital Buenos Aires with $48 \mathrm{~h}$ of life due to pneumoperitoneum more than 12 hours ago, with no defined cause. She was in the air in another hospital, without reports of positive pressure ventilation or resuscitation. Ceneral, Regular, jaundiced Kramer Zone II, tachypsisic, hypoactive, reactive to stimuli, with borderline perfusion was present. Distended, globular, shiny abdomen with periumbilical hyperemia. A laparotomy with supraumbilical transverse incision was performed, showing gastric rupture and gastrorrhaphy on two planes and intra-cath passage in subclavian. Procedure completed without intercurrences. Patient is in a NICU (intensive care unit neonatal), severe, intubated, evolving with fever and jaundice. FINAL CONSIDERATIONS: Neonatal gastric perforation, although rare, is an extremely serious and serious condition that should be addressed early. Thus, the importance of its study and investment to improve diagnosis, support and surgical correction is denoted, in order to reduce its mortality and improve the prognosis of patients.

\section{DIFFICULTY IN THE DIAGNOSIS OF TUBERCULOSIS}

Yasmim Fernandes Mota da Rocha', Maria Eduarda Carvalho Santos de Araújo², Miriam Marques Nogueira Rocha', Joana Elisabeth de Sousa Martins Freitas', Charles Conçalves Barroso de Sousa', Caio Macêdo de Carvalho'

' Facid Devry, 2 State University of Piaui

INTRODUTION: The tubercolulosis is a patology caused by bacterias of Mycobacterium gender.The form of transmission happens by infeccious particles in the air. In our body, the bacteria develops itself in the airways, where it can be phagocytosed by macrophagus and have an intracellular parasite activity. it can, futhermore, make the person manifeste symptoms, like fever, tiredness and cough productive or not. It is hard to give the correct diagnosis, because the tuberculine test does not informs if you have necessarially the illness. This, because if the pacient has imunodepression, the test result may be false negative because the protein injected causes imune response, the the sputum smear microscopy not always gives a confirmatory result. This relate of case shows the dificulties of getting a correct tuberculosis diagnosis. RELATE OF CASE: L. M. 0. C. Man, 22 years old, showed dry and long-lasting cough besides tiredness. after the crisis of cough, he went to the SESP in Marabá-PA, receiving unffective tratment. it was requested an $X$ ray, that showed a lesion caracteristic of tuberculosis. it was requested a sputum smear microscopy, that had no result for bacillus resistent to acid and alcohol. Also, the HIV-test had negative result. During this period, the pacient had an alergic process, with spots on the chest, back and upper limbs. He moved to Teresina-PI, where he was sent to a pneumologist. The doctor requested a thoracic computerized tomography, that reveled two nodules in the lower lobe of the right lung. it was made a lobectomy, so the byopsia could be realized. The pathologist identified a granulomatous chronic inflammatory process, with central caseous necrosis, without neoplasic cells. . After the cirurgy, the pacient informed end of the symtoms. He had a diagnosis of non-bacillary nodular pulmonary tuberculosis and sent no iniciate the tratment. FINAL CONSIDERATIONS: We can conclude with this relate of case that the dificulties on giving this pacient a correct diagnosis happens because of the symtoms non-specificity and the negativity of the tests made. Besisdes, the many times the pacient went to the hospital shows us that the health profissionals aren't well prepared to combate tuberculosis.

\section{LAPAROSCOPIC INGUINAL HERNIORRHAPHY IN CHILDREN}

Alexandre Gabriel Silva Rego', Brenda Irla Soares Santos ${ }^{1}$ Mariah Zanetti de Holleben Mello², Fábio Augusto Zama Cavalheiroº ${ }^{2}$ Bruno Pinheiro Falcão'

Federal University of Piauí, ${ }^{2}$ Hospital of Rocio

INTRODUCTION: Congenital inguinal hernia is a disease of the most difficult surgical treatment observed in children, being an open inguinal herniorrhaphy, a procedure dating back 25 years after Christ, the treatment of choice. Laparoscopic repair of inguinal hernia in children has become an alternative to the conventional open procedure and may reduce postoperative pain, improve aesthetic outcome, allow manipulation of the structures of the smart cord and provide easy access to the contralateral internal inguinal ring. By means of technique, by percutaneous technique, of the authors, by the percutaneous technique, by authors and pharmacists. CASE REPORT: Presenting the cases of three girls diagnosed with indirect inguinal hernia submitted to videolaparoscopic surgical correction by percutaneous technique. Through the visualization of the pelvis by a $5 \mathrm{~mm}$ optic inserted by navel, a periphery was performed around the internal inguinal ring extended, with the aid of a Tuohy 22 Gauge epidural needle and a non-absorbable monofilament wire (polypropylene 2.0) closing the defect completely. As children between 6 and 8 years, between 18 and 23 kilograms and associated comorbidity. Surgical times were progressively shorter (29,24 and 20 minutes), as children were discharged without the same procedure day and required controlled analgesia only not in the immediate postoperative period, returned to school after 3 days and did not present any complication intra or postoperative period, with a follow-up of 10 months. FINAL CONSIDERATIONS: Congenital inguinal hernia remains a disease of more frequent surgical treatment in children, present daily in the clinical practice of pediatricians. Despite its consecrated surgical treatment, it is not free of complications. We introduced a new minimally invasive surgical approach, supported by the literature, with a potential to reduce spermatic cord injury, with no alteration in response rates and improvement of aesthetic outcome.

\section{GUILLAIN-BARRÉ SYNDROME}

Yasmim Fernandes Mota da Rocha', Caio Macêdo de Carvalho', Charles Gonçalves Barroso de Sousa', Maria Eduarda Carvalho Santos de Araújo², Miriam Marques Nogueira Rocha', Joana Elisabeth de Sousa Martins Freitas'.

1 Facid Devry, ${ }^{2}$ State University of Piauí

INTRODUCTION: Guillain-Barré syndrome is a peripheral neuropathy from autoimmune origin marked by the loss of myelin sheath and tendon reflexes, through a mechanism of molecular mimicry. The incidence is from one to two cases per 100.000 people. The symptoms are usually paresthesia, pain and paresis in the lower limbs, in addition to nausea and vomiting. Some of the agents associated with this syndrome are Campylobacter jejuni, Cytomegalovirus, Zika Virus and Plasmodium Falciparum. Regardless of being A serious disease, it has a good prognosis, since $85 \%$ of treated patients recover completely. CASE REPORT: Patient F. R. S., male, age 55 , diagnosed with malaria 3 times over a period of 10 years. On May 17, 2016, he sought the Basic Health Unit of the Poty Velho neighborhood - Teresina / PI, reporting that he had started a scenario of 4-month-old loss of muscle strength in the hands and lower limbs. It was reported that the patient had been hospitalized in Porto Velho-R0, where he worked for 40 days until April 18, 2016. He was discharged, having been prescribed antihypertensive medications and being also diagnosed with urinary infection. Patient was wheelchair-bound and tretaparético. He was being fed with difficulty, became incapacitated for locomotive activities indefinitely and was diagnosed with GuillanBarré Syndrome. According to the theory of molecular mimicry in which contact with the infectious pathogen can lead to this crossreaction, malaria infection may have been the factor that provided such mimicry. The patient, having complete adherence to the medical treatment and attending the physiotherapist frequently, showed a picture of improvement, since he is in good general condition and already feeds independentlyduring the treatment. FINAL CONSIDERATIONS: The patient's main complaint about loss of strength was the main indicator for the clinical diagnosis of Guillan-Barré Syndrome. Although this syndrome does not have an elucidated cause and there is still no cure for the patients affected by it, it is observed the importance of diagnosis and medical follow-up, increasing the quality of life of the patients, contributing to their general health. 


\section{ANGIOMATHOID FIBRO-HISTIOCITOMA}

Alexandre Gabriel Silva Rego', Antonio Rayron Soares de Holanda', Clarissa Cunha Vilanova', Rafel de Deus Moura'. Federal University of Piauí

INTRODUCTION: Angiomatoid fibrous histiocytoma (FHM) is a rare dermatofibroma in the literature characterized by its rarity (less than $2 \%$ ) and its importance in the differential diagnosis with other tumors. Its etiology is unknown, but it is believed to be related to the extravasation of red blood cells from the vascular wall into the vascular cystic spaces. This is due to repeated microtraumas that dissect areas of the tumor forming characteristic fissures and leading to haemosiderin phagocytosis by tumor cells. It has a size between $0.5-2 \mathrm{~cm}$ in diameter, smooth or scaly surface and color ranging from dark red to brown or black. It is difficult to diagnose before excision and anatomopathological, with a reserved prognosis in some cases. CASE REPORT: A 21-yearold patient, from Teresina-PI, a driver's helper, single, denies previous illnesses, does not use medication for continuous use, denies allergies, socially drinks, does not smoke, in the HU-UFPI complaining of lump in the scalp. He reports that he has had two surgeries for excision of the same, but always presenting recurrence. On physical examination, he presented Ceneral Good, conscious and oriented, eupneic, afebrile, good nutrition and hydration and referred to normal appetite and eliminations. Established diagnostic hypothesis for sebaceous cyst. Ultrasound of Haired Leather was requested, which showed a hypoechoic lesion of $2.5 \times 2.1 \mathrm{~cm}$ that established the conduct of small surgery to exertion of the lesion, with referral of the material to pathology with suspicion of sebaceous cyst that showed to be low-grade fusocellular neoplasia of $1,6 \mathrm{~cm}$ (largest axis), with up to 2 mitoses / 10 CGA (large increase fields), without tumor necrosis and angiolymphatic invasion with free and narrow surgical margins (1.0 $\mathrm{mm}$ from the lesion). The histological picture suggested the possibility of FHM that was sent to immunohistochemistry that showed CD68 positive, confirming the diagnosis. FINAL CONSIDERATIONS: FHM rarely has distant and lymph node metastases. Complete surgical resection without adjuvant therapies is the treatment of choice for most of these tumors, and it can often be confused with vascular or melanocytic tumors, and the exact diagnosis of the lesion is of utmost importance. prognosis of the patient.

55. INTESTINAL TUBERCULOSIS SIMULATING CROHN'S DISEASE

Igor Iann Ponte Parente', João Victor de Oliveira Raulino', Jaqueline de Andrade Fonseca', Antonio Ricardo de Oliveira Lima', Matheus Miranda Dias', Felipe José Mendes Raulino Neto².

Facid Devry, ${ }^{2}$ Federal University of Piauí

INTRODUCTION: Tuberculosis is an infectious disease of chronic evolution caused by Koch's bacillus and transmitted predominantly by air. The bacillus has a preference for the lungs, but can affect other areas, such as intestine, producing a hypersensitivity response in the body evidenced by positive tuberculin test. The spread of the disease is directly related to the socioeconomic conditions of the population, being more common in third world countries. Intestinal tuberculosis (IT) usually occurs in nations where tuberculosis is prevalent, mainly affecting local immunosuppressants, especially after the HIV epidemic. Despite its rarity in the population with pulmonary tuberculosis in the early twentieth century, it was the main cause of stenosis and intestinal obstruction. In Brazil, IT is more commonly associated with the presence of active or scarred pulmonary lesions, and may occur without any previous disease. Thus, IT is often confused with other conditions such as Crohn's disease and neoplasms. CASE REPORT: Patient G.S.S., a 56-year-old man, a brown man, born in Boa Vista-RR, consulted in Teresina-PI complaining of diffuse colicky abdominal pain that persisted for a year and worsened in the last months preceding the consultation. He also reported that the pain was intensified in the right iliac fossa (RIF), in addition to weight loss (not knowing how to quantify) and chronic diarrhea. A tomography scan was performed in Boa Vista, which showed thickening of the walls of the cecum, and a physical examination found a palpable mass in RIF. Colonoscopy was performed at a private service in Teresina, where an ulcer-stenosing lesion was detected in the ileo-cecal valve. The biopsy of the lesion showed granulomatous colitis with foci of necrosis and the BAAR survey was positive, and these findings were compatible with TI. FINAL CONSIDERATIONS: The presentation of TI occurs, preferably, in the terminal ilium and cecum with nonspecific symptomatology, corroborating with the presented case. Knowing this, it is fundamental to make an early diagnosis of this disease and to know how to conduct the patient in situations such as this, always having to evaluate the clinical conditions of the patients and look for a history of tuberculosis. The patient is under clinical treatment waiting for a control colonoscopy.

\section{EPIDEMIOLOGICAL PROFILE OF HUMAN VISCERAL} LEISHMANIOSIS IN THE STATE OF MARANHÃO BETWEEN 20072015

Antonio Joatan de Barros Filho', Wanderson Mario Cavalcante Olimpio ${ }^{2}$, Francisley Monte da Costa', Manoel Filipe Dias Nery', Sueli de Souza Costa².

7 Federal University of Maranhão, ${ }^{2}$ UNINOVAFAPI University Center

INTRODUCTION: Visceral leishmaniasis (VL) is a chronic, severe, highly lethal disease and a major problem for Public Health in Brazil, which is notable for the large number of reports registered in the State of Maranhão (MA). OBJECTIVE: To establish the epidemiological profile of VL incidence in Maranhão from 2007 to 2015 according to the criteria: sex, age, evolution and municipality of infection. METHODS: This was a descriptive quantitative study based on data obtained from the Department of Informatics of the Unified Health System (DATASUS), corresponding to the period from 2007 to 2015. It was analyzed the incidence of cases in the state, and the relationships with year, municipalities, age group, sex and evolution of the disease. The results were grouped into Microsoft Excel spreadsheets and exposed in charts and tables. RESULTS: During the study period, there were 4,632 confirmed autochthonous cases of VL in Maranhão. The annual average was 514.66 cases / year. In the period, the highest number of registrations in the State was in 2013 (708) and the lowest in 2012 (342). Of the 117 municipalities that registered cases, the capital São Luís is responsible for a greater number of cases with $1261(27.22 \%)$, followed by the municipality of Imperatriz with 328 cases $(7.08 \%)$. The infection rates were higher in the male gender, 2,879 cases $(62.15 \%)$ and the most affected age group were children aged 1 to 4 years, with $36.16 \%$ of the cases (1675), followed by adults aged 20 to $3918.6 \%$ (862). The cure rate was $53.54 \%$ (2480). The mortality rate for the disease in this period was $6.67 \%$ (309), of these $25.24 \%$ (78) were adults in the age group of 20 to 39 years. DISCUSSION: Of the 117 municipalities that have registered cases, the capital São Luís is responsible for a greater number of cases, a result that may be related by factors such as urbanization, the supply of human and animal food sources, abundant afforestation, breeding sites or garbage accumulations. The infection rates are higher in the male gender, and may be related to work activity in the rural area. The most affected age group was children aged 1 to 4 years. The reason for the greater susceptibility of the children is explained by the relative cellular immaturity, aggravated by malnutrition, which is so common in endemic areas, as well as a greater exposure to the vector in the peridomestic.CONCLUSION: It was identified in the present research that the epidemiological profile of VL is more frequent in males, in the age group of 1-4 years and more reported in the state capital: São Luís. Allowing to conclude that public measures aimed at prevention are essential, at the moment for the state of the disease in the State.

\section{ANALYSES OF AVASCULAR TUMOR GROWTH THROUGH COMPUTATIONAL MODELINC GOVERNED BY BIOLOGICAL CONCEPTS}

Rodrigo Gondim Miranda', Bruna Benigna Sales Armstrong', Mayara de Moura Borges', Salmon Rocha Alencar ${ }^{1}$, Sthefany da Fonseca Leal', Lis Cardoso Marinho Medeiros'.

' Federal University of Piauí

INTRODUCTION: Under normal conditions, the cells of our body grow, divide, die and are replaced in an orderly and controlled manner. But if the process gets out of control, the cells grow 
rapidly and a lump called a tumor can develop. As the tumor grows, it becomes more difficult for the nutrients to reach the nucleus of the tumor, since the outer cells tend to consume these nutrients first. Eventually, cells near the nucleus may become so deficient that they lose the ability to be proliferative and enter the quiescent stage. As the tumor increases, prolonged nutrient deficiency can cause the cells near the nucleus to die, forming a group of dead cells known as the necrotic nucleus. The tumor growth described so far is limited to the early stage in which the tumor has not yet developed its own blood vessels, ie, an avascular tumor. OBJECTIVES: To analyze the growth of avascular tumor by means of a computational modeling. METHODS: Sherratt and Chaplain formulated a model in terms of cell density of proliferating, quiescent and necrotic cells in a one-dimensional domain in space. Recently, Tan and Ang modified the model to include random variation in cellular processes. This model provides a more realistic description of avascular tumor growth through the use of random terms in the equations of the model. The model chosen is the Sherratt-Chaplain model and its variants, proposed by Tan and Ang. RESULTS: The images obtained in the results are pooled to provide an animation of tumor growth. From the proposed mathematical modeling, the tumor begins with a high concentration of proliferating cells and a relatively small concentration of quiescent and necrotic cells. This changes gradually as the time variable increases. When time increases above a threshold, a necrotic nucleus begins to form. CONCLUSION: The model for avascular tumor growth, proposed by Sherratt and Chaplain, is solved and implemented using a finite difference scheme. The results are presented in the form of graphs and as a series of tumor images for better visualization. It was observed that the computational model implemented under the light of mathematical and biological concepts was satisfactory contemplating the evolution of avascular tumor growth.

58.

\section{CLINICAL AND EPIDEMIOLOGICAL PROFILE OF CHIKUNGUNYA FEVER IN THE STATE OF PIAUI IN 2016}

Cristiane Vieira Amaral, Hildenise Sávia de Sousa Almeida', Jerrison da Silva de Morais', Herion Alves da Silva

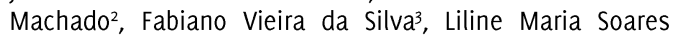
Martins'.

' State University of Piauí, 2 Facid Devry, 3 Federal University of Piauí

INTRODUCTION: Chikungunya fever is part of the group of emerging and reemerging infectious diseases, and is currently considered a major public health challenge. It is characterized by a sudden and debilitating onset of fever, as well as by the intensity of strong joint pains. In Brazil, the first cases emerged in 2010, and those of autochthonous origin appeared only four years later, in Amapá. Since then, the number of confirmed cases has been growing, alarming public health authorities on the need for effective prevention measures. OBJECTIVES: To describe the epidemiological profile and the signs and symptoms of patient laboratory confirmed as reagents for the chikungunya virus (CHIKV), in Piauí, in 2016. METHODS: Retrospective descriptive study, carried out in a reference laboratory in public health in the state of Piauí. A total of 168 notification forms for chikungunya containing all the necessary data for the survey were selected. The project was carried out with the approval of the research ethics committee. RESULTS: The female gender was the most prevalent in CHIKV positive patients $(69.65 \%)$ and it was noted that this incidence gradually increased with age, so that $47 \%$ of the cases were older than 31 years. As to the origin, most of them ( $44.65 \%$ ) were from Teresina, followed by Parnaíba (20.23\%), São João da Fronteira (12.5\%) and Altos (9.5\%). About $92.25 \%$ were from the urban area. The most common signs and symptoms were fever $(97.6 \%)$, myalgia $(89.9 \%)$, headache $(72 \%)$, severe arthralgia $(69.7 \%)$, back pain (51.2\%) and rash (47\%). Hemorrhagic, neurological, and conjunctival hyperemia events occurred less frequently. The predominant presentation forms were subacute ( $49.4 \%)$ and acute $(48.2 \%)$. The chronic form represented the minority of cases $(2.4 \%)$. CONCLUSION: We concluded that in 2016, the chikungunya fever showed a higher incidence in females, increasing proportionally with age. Teresina had the highest number of cases, especially in urban areas. Fever, headache and severe arthralgia were the most observed symptoms and the disease predominantly manifested in the subacute form. To determine the frequency of positive cases and their origin is of great importance for the adoption of educational and prophylaxis measures for CHIKV.

\section{EXPERIENCE REPORT OF A YELLOW MAY CAMPAIGN MADE} WITH SOBRAL CYCLISTS

Wylston de Moraes Caldas Filho', Jhonyson Antonio Oliveira Marques', Gabriel Luan Batista de Ávila', Geison Vasconcelos Lira', Diulio da Silva Portela', Igor Jungers'

$\checkmark$ Federal University of Ceará

INTRODUCTION: In Ceará, 2,620 deaths from traffic accidents were counted by Detran in 2016, several of them may be avoided with adequate awareness of the population. The city of Sobral has one of the highest rates of traffic accidents and deaths in the country. With this in mind, the Nucleus of Medical Development of Sobral (NUDEMES) of the Medical Course of the Federal University of Ceará of the campus of Sobral created the Cycle Tour for Peace directed to the cyclists. Cyclists are a risk group due to the severity of a major injury in the event of an accident with another vehicle. This Tour is intended to raise awareness among Sobral's population about cyclists, respecting their right to ride on the streets, as well as transmit information to cyclists themselves. OBJECTIVE: Organize the cycling tour to raise awareness among the population of cyclists, car and motorcycle drivers in Sobral on the prevention of traffic accidents, from the point of view of cyclists. METHODOLOGY:The action was developed on May 15 at Padre Fialho street number 227. The local was established due to a partnership between NUDEMES and a private health institution to contribute to the organization. 8 cycling groups of Sobral were also contacted for the tour, totaling approximately 100 cyclists. The public was chosen due to the lack of attention given to this population during the traffic campaigns carried out that month. The awareness of cyclists is important for other reasons, such as the lack of training on traffic laws for most cyclists who do not have any type of training at driving schools. A folder was made and delivered while the concentration of cyclists was held. RESULTS: As the result was perceived by NUDEMES students, they had the opportunity to interact with the population in a positive way, where they prioritized the exchange of experiences and learning. Many of them have reported that there is still a lot of disrespect between drivers and cyclists. CONCLUSION: Considering the importance of preventive action, as one of the bases of basic attention, the campaign of the Cycle Tour For Peace in Sobral was considered a success by the members of the league and the participants of the cycling community.

60. EVENT EMPATHY: STRATEGY FOR THE IMPROVING OF THE PATIENT MEDICAL RELATIONSHIP

Gabriel Luan Batisita de Ávila', Jhonyson Antonio Oliveira Marques', Wylston de Moraes Caldas Filho', Rodrigo Marques Queiroz', Denise Helena Aparecida da Silva Vieira', Geison Vasconcelos Lira'.

'Federal University of Ceará

INTRODUCTION: The patient medical relationship has undergone constant changes over time. The quality of this relationship depends on the ability and ability of health professionals to adapt to the subjective changes of each patient. This relationship is fundamental for the doctor's work to be effective. Among the various aspects that are part of the patient physician relationship, empathy is among those that deserve attention. With the objective that medical students could have a global education, not only for technical knowledge, the extension project Nucleus of Medica Development of Sobral (NUDEMES), an academic League of the Medicine College of the Federal University of Ceará (UFC), Sobral campus, developed a lecture called EMPATIA, in which a guest who has had health problems gave his testimony, emphasizing how he felt during his treatment and the care given by the doctors who took care of her. OBJECTIVE: Relate empathy and the process of illness, being a way of perfecting the patient doctor relationship. METHODOLOGY: The event took place on $11 / 29 / 2016$ in the auditorium of the Medicine College (UFC), Sobral campus. A 
Abstracts

lecturer, a medical student, was invited to discuss her leukemia cure process and how she was treated by the doctors who participated in her treatment. Students, teachers and health professionals participated, totaling approximately 50 people. Next, a discussion thread was set up in which all participants could ask the speaker questions and set out their own experiences on how empathy can influence therapeutic efficacy. RESULTS: After the talk can be perceived by the opinion of those present that empathy in the patient physician relationship is important because it brings more safety to the patient, resulting in a more complete interaction of the patient, who feels more comfortable to talk about their problems, symptoms and possible doubts. CONCLUSION: It is necessary for medical schools to constantly teach humanistic skills to their students, so that they can practice integral medicine and have continued contact with their patients. In this way, EMPATIA was an exercise that allowed the present scholars to self-evaluate and try to put themselves in the place of those who were in one of the worst phases of their life.

61. POSTOPERATIVE GASTRIC SYMPTOMS OF BARIATRIC SURGERY: COMPARISON OF VERTICAL GASTRECTOMY AND GASTRIC BYPASS TECHNIQUES

Ana Maria Vilarinho Evangelista', Isadora Ferro Nogueira², Lucas Noleto Lima', Guilherme Miranda Correia', George Henrique Rodrigues dos Santos', Gustavo Santos de Sousa'.

7 Facid Devry, 2 Federal University of Piaui

INTRODUCTION: Obesity is a chronic disease defined by excess body fat and diagnosed by calculating the body mass index. The surgical treatment consists of bariatric surgery, whose indications are: morbid obesity, grade II obesity associated with comorbidities, and clinical treatment failure. The most commonly used surgical techniques are vertical gastrectomy (Sleeve) and Roux-en-Y gasplasty (gastric bypass). There are many unpleasant symptoms after the ingestion of certain foods in the postoperative period of this surgery, from nausea and vomiting to food impaction. OBJECTIVE: The objective is to compare the techniques of vertical gastrectomy and gastric bypass regarding the presence of gastric symptoms in the postoperative period. METHODOLOGY: The project was initiated after appreciation and release of the CEP - FACID and through the signing of the Term of Commitment of Data Use. This is a cross-sectional and quantitative descriptive study in which data were collected from records of 43 patients submitted to bariatric surgery using the Sleeve and Gastric Bypass techniques between January 2013 and June 2014 in a private clinic of the city of Teresina-PI. The data were organized into individual records (name, age, sex, surgery information and gastric symptoms in the postoperative period), distributed in Microsoft Excel ${ }^{\circledR} 2017$ tables and analyzed using the Pearson statistical correlation test, whose significance level was adopted was p,0.05. RESULTS: Among the patients submitted to the Sleeve technique, $46,7 \%(p=0,0023)$ had regurgitation and $43,3 \%(p=0,0000)$ heartburn. In the postoperative period, the most prevalent symptoms were regurgitation $(61,5 \%$; $p=0,0023)$, nausea $(61,5 \% ; p=0,0000)$ and food impaction $(53,8 \%$; $p=0,0000)$. Another symptom evaluated was vomiting. of the patients submitted to the Sleeve technique, $40 \% \quad(p=0,0482)$ reported never having had an episode of vomiting, compared to $23 \%(p=0,0482)$ of those submitted to gastric bypass. CONCLUSION: Food regurgitation and heartburn are the most common gastric symptoms in patients undergoing the Sleeve, while the other group most commonly presents with regurgitation, nausea and food impaction. of the patients operated by vertical gastrectomy, $40 \%$ never had an episode of vomiting. 